\title{
A THEORETICAL ANALYSIS OF \\ POPULATION GENETICS OF PLANTS ON RESTORED HABITATS
}

\author{
Alexander G. Bogoliubov \\ Botanical Institute, Russian Academy of Science, \\ St. Petersburg, Russia \\ Craig Loehle \\ Environmental Research Division \\ Argonne National Laboratory, \\ Argonne, IL 60439 USA
}

\section{RECEIVED \\ FEB 171995 \\ OSTI}

ABSTRACT

Seed and propagules used for habitat restoration are not likely to be closely adapted to local site conditions. Rapid changes of genotypes frequencies on local microsites and/or microevolution would allow plants to become better adapted to a site. These same factors would help to maintain genetic diversity and ensure the survival of small endangered populations. We used population genetics models to examine the selection of genotypes during establishment on restored sites. Vegetative spread was shown to affect selection and significantly reduce genetic diversity. To study general microevolution, we linked a model of resource usage with a genetics model and analyzed competition between genotypes. A complex suite of feasible ecogenetic states was shown to result. The state actually resulting would depend strongly on initial conditions. This analysis indicated that genetic structure can vary locally and can produce overall genetic variability that is not simply the result of microsite adaptations. For restoration activities, the implication is that small differences in seed source could lead to large differences in local genetic structure after selection.

\section{DISCLAIMER}

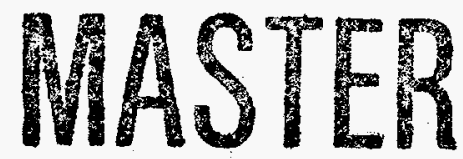

\footnotetext{
This report was prepared as an account of work sponsored by an agency of the United States Government. Neither the United States Government nor any agency thereof, nor any of their employees, makes any warranty, express or implied, or assumes any legal liability or responsibility for the accuracy, completeness, or usefulness of any information, apparatus, product, or process disclosed, or represents that its use would not infringe privately owned rights. Refermanufacturer, or specific commercial product, process, or service by trade name, trademark, mendation, or fayring does not necessarily constitute or imply its endorsement, recomand opinions of authors expressed States Government or any agency thereof. The views United States Government or any agency thereof
} 


\section{DISCLAIMER}

Portions of this document may be illegible in electronic image products. Images are produced from the best available original document. 


\section{INTRODUCTION}

As we look beyond the restoration of small areas like damaged wetlands or mined areas, we can see that larger-scale restoration is becoming necessary or is already in progress, as in Costa Rica. In addition, whereas rare and introduced plants are now typically protected by protecting their habitats, preserving these species will increasingly require reintroducing them, a practice that is infrequent at present. The genetic properties of the species must be considered for either large-scale restorations or reintroductions of rare species. The genetics of endangered animal populations is often considered (Meffe and Carroll, 1994), but this factor is not often taken into account for plants. For example, a standard text on restoration of disturbed lands (Munshower, 1993) does not mention genetics or seed provenance.

Genetics bears upon three primary restoration questions: survival and persistence on the site, genetic diversity, and microevolution on the site. Survival and persistence can be problematic for introduced plants. If proper pollinators are not present, long-term persistence is threatened, though clonal growth may still be possible. If seeds are introduced from a variety of sources, first-generation offspring may be nonviable due to outbreeding depression (Templeton, 1986) or may have combinations of traits that put them at a disadvantage. Genetic diversity is also of concern particularly in small populations where inbreeding depression is possible (Ellstrand and Elam, 1993). However, merely introducing seed from a wide variety of sources does not ensure genetic variability. If most of the introduced genotypes are poorly adapted to local site conditions, then the initial impression of diversity will be illusory, because one can expect that most of the genotypes will be rapidly eliminated. Both of these first two issues are related to the intensity and rate of microevolution. Because plants are fixed in place, adaptation of subpopulations to local soils and microclimates is potentially very important. When a large area is cleared, we eliminate this spatial component of the population genetic structure. A very important question is how rapidly this spatial genetic structure can be restored by microevolution or spatial sorting of genotypes. The rate of this process affects both population persistence and 
genetic diversity. Microevolution, however, is probably strongly affected by plant longevity, clonal reproduction, and the nature of selection in an introduced and diverse gene pool.

In the absence of knowledge with which to identify genotypes of a species specifically adapted to microsites within a habitat, common practice is to introduce a mixture of seed from different sources (Meffe and Carroll, 1994). The rationale is that this should provide sufficient genetic variability for natural selection to identify the best genotypes for the locality and for microsites. The analogy between the selection of introduced species and the selection of genotypes, however, is misleading, because (1) offspring of introduced plants will possess mixed genomes, and (2) except for discrete traits like heavy-metal tolerance, genetic traits are typically not arranged like beads on a string that can be easily sorted but rather are part of coadapted gene complexes, so that resorting mixed genomes into ecotypes might be very slow.

Because introduced plants interbreed, the offspring of plants introduced from diverse localities may exhibit outbreeding depression or even hybrid sterility (Ellstrand and Elam, 1993; Ledig, 1986; Templeton, 1986). Many plants exhibit strong genetic gradients (over scales of meters) corresponding to edaphic gradients (Ledig, 1986) such as those resulting from changes in elevation. For example, gradients of heavy-metal-tolerant plant genotypes may occur at the edge of a contaminated zone and on edges of serpentine soils (McNeilly, 1988). Because of this frequent adaptation to specific microsites, the crossing of introduced plants from a mixture of localities is likely to result in outcrossing depression. In particular, there is no guarantee that $F_{1}$ offspring will be well-adapted to any local microsite, because they may possess some traits advantageous on a drier site and some traits adaptive for a cooler site, etc. For example, the offspring of Austrian and Turkish ibex introduced into the Tatra mountains of Czechoslovakia gave birth in February, the coldest month, and subsequently became extinct (Greig, 1979). The potential for hybridization in plants is also greater, on disturbed sites, and multiple-species, largescale hybridization of oaks has been observed in southern Illinois, USA, on large tracts of reclaimed strip-mined land (Ashby, 1987; R. M. Miller, personal communication). As noted 
above, sorting a mixture of genomes resulting from crossing and hybridization into locally adapted ecotypes is far from straightforward and might be possible only in evolutionary time.

In this paper we analyze these issues by using population genetics models. Our results have significant implications for restoration practice. First, we examine the effects of clonal reproduction. Second, we analyze microevolutionary processes in the context of restoration.

\section{GENETIC EFFECTS OF CLONAL REPRODUCTION IN INTRODUCED POPULATIONS}

Vegetative reproduction has significantly different results for introduced plant populations versus animals. Once established, clonal plants can survive and spread even if they cannot reproduce successfully. Restoration experience has shown that large clonal patches are often observed on restored sites like the Curtis Prairie (University of Wisconsin) whereas they are uncommon on nearby prairie remnants (Powers, 1988). In this section we explore the population genetics consequences of vegetative spread in the context of restoration.

Consider the dynamics of a single-species population and assume that it obeys the logistic law of population growth. In spite of its high conventionality and a number of evident drawbacks, the logistic equation still mimics certain properties of an isolated, invading population. What might be the dynamics of genotype and allele frequencies if we assume the organisms to be diploid? In this context, the Fisher approach to description of the dynamics in the population genetic structure is generally not correct (Kostitzin, 1938; Svirezhev and Passekov, 1982; Abrosov and Bogoliubov, 1988; Bogoliubov, 1991).

We let the population density be denoted by $N$, the frequency of genotype $(i, j)$ by $u_{i j}$, and the frequency of allele $i$ by $p_{i}=\sum_{j=1}^{m} u_{i j}$, where $m$ is the number of allele states at a given locus. If the locus is assumed to be neutral with respect to its influence on population growth, the per capita growth rate of the whole population can be modeled as

$$
f(N)=\alpha+\gamma-\beta N
$$


where $\alpha$ is a specific rate of sexual reproduction, $\gamma$ is a specific rate of asexual (clonal) reproduction, and $\beta$ reflects the limitation of population growth by intraspecific competition, or a population's self-regulation by its size or density.

The logistic growth equation would thus take the following form:

$$
\mathrm{dN} / \mathrm{dt}=(\alpha+\gamma-\beta \mathrm{N}) \mathrm{N}=\mathrm{f}(\mathrm{N}) \mathrm{N}
$$

On the contrary, the population genetics approach implies that each genotype $(i, j)$ is characterized by its own specific rate of sexual reproduction, $\alpha_{\mathrm{ij}}$ and asexual reproduction, $\gamma_{\mathrm{ij}}$, and by its own rate of density self-regulation, $\beta_{\mathrm{ij}}$. Therefore, the per capita growth rate for the group of genotype $(i, j)$ individuals is given by

$$
f_{i j}(N)=\alpha_{i j}+\gamma_{i j}-\beta_{i j} N .
$$

The conditions of symmetry

$$
\alpha_{i j}=\alpha_{j i}, \gamma_{i j}=\gamma_{j i}, \beta_{i j}=\beta_{j i}
$$

mean that the genotypes $(i, j)$ and $(j, i)$ are equivalent.

The average per capita growth rate of the total population whose genotype composition is given by $\mathrm{m}^{2}$-vector

$$
\mathbf{u}=\left[\mathrm{u}_{11}, \ldots, \mathrm{u}_{\mathrm{ml}}, \mathrm{u}_{21}, \ldots, \mathrm{u}_{2 \mathrm{~m}}, \ldots, \mathrm{u}_{\mathrm{ml}}, \ldots, \mathrm{u}_{\mathrm{mm}}\right]
$$

of genotype frequencies $u_{i j}\left(\sum_{i=1}^{m} \sum_{j=1}^{m} u_{i j}=1\right)$, is respectively equal to

$$
\bar{f}(N, u)=\sum_{i=1}^{m} \sum_{j=1}^{m} f_{i j}(N) u_{i j}
$$

or

$$
\overline{\mathbf{f}}(\mathbf{N}, \mathbf{u})=\bar{\alpha}(\mathbf{u})+\bar{\gamma}(\mathbf{u})-\bar{\beta}(\mathbf{u}) \mathbf{N},
$$

where

$$
\bar{\alpha}(\mathbf{u})=\sum_{\mathrm{i}=1}^{\mathrm{m}} \sum_{\mathrm{j}=1}^{\mathrm{m}} \alpha_{\mathrm{ij}} \mathrm{u}_{\mathrm{ij}}
$$

is the average specific rate of sexual reproduction,

$$
\bar{\gamma}(\mathrm{u})=\sum_{\mathrm{i}=1}^{\mathrm{m}} \sum_{\mathrm{j}=1}^{\mathrm{m}} \gamma_{\mathrm{ij}} \mathrm{u}_{\mathrm{ij}}
$$


is the average specific rate of vegetative reproduction, and

$$
\bar{\beta}(\mathbf{u})=\sum_{\mathrm{i}=1}^{\mathrm{m}} \sum_{\mathrm{j}=1}^{\mathrm{m}} \beta_{\mathrm{ij}} \mathrm{u}_{\mathrm{ij}}
$$

is the average rate of density self-regulation.

The population dynamics equation then takes the following form (Abrosov and Bogliubov, 1988):

$$
\mathrm{dN} / \mathrm{dt}=[\bar{\alpha}(\mathbf{u})+\bar{\gamma}(\mathbf{u})-\bar{\beta}(\mathbf{u}) \mathrm{N}] \mathrm{N} .
$$

At the same time, we are interested in the dynamics of group density, denoted by $\mathrm{N}_{\mathrm{ij}}$, of individuals carrying genotype $(i, j)$, with the total population density being $N=\sum_{i=1}^{m} \sum_{j=1}^{m} N_{i j}$ and the density composition given by $\mathrm{m}^{2}$-vector

$$
\mathbf{N}=\left[\mathrm{N}_{11}, \ldots, \mathrm{N}_{\mathrm{m} 1}, \mathrm{~N}_{21}, \ldots, \mathrm{N}_{2 \mathrm{~m}}, \ldots, \mathrm{N}_{\mathrm{ml}}, \ldots, \mathrm{N}_{\mathrm{mm}}\right] \text {. }
$$

The corresponding equations for $\mathrm{N}_{\mathrm{ij}}$ can be written as follows (Abrosov and Bogoliubov, 1985, 1988):

$$
d N_{i j} / d t=f_{i j}(N) N_{i j}+\varphi_{i j}(N),
$$

where

$$
\varphi_{i j}(N)=\frac{\sum_{k \neq i} \sum_{s \neq j}\left(\alpha_{i s} \alpha_{k j} N_{i s} N_{k j}-\alpha_{i j} \alpha_{k s} N_{i j} N_{k s}\right)}{\sum_{k, s} \alpha_{k s} N_{k s}},
$$

In equations (2.12) all values $\mathrm{N}_{\mathrm{ij}}$ are nonnegative and in virtue of (2.13) they don't simultaneously vanish (become zero). In frequency form function $\varphi_{i j}(N)$ has the following form:

$$
\varphi_{\mathrm{ij}}(\mathbf{u}, \mathbf{N})=\mathrm{N} \psi_{\mathrm{ij}}(\mathbf{u}),
$$

with

$$
\psi_{\mathrm{ij}}(\mathbf{u})=N \frac{\sum_{\mathrm{k \neq i}} \sum_{s \neq j}\left(\alpha_{i s} \alpha_{k j} \mathrm{u}_{i s} \mathrm{u}_{\mathrm{kj}}-\alpha_{\mathrm{ij}} \alpha_{\mathrm{ks}} \mathrm{u}_{\mathrm{ij}} \mathrm{u}_{\mathrm{ks}}\right)}{\bar{\alpha}(\mathrm{u})} .
$$

Function $\psi_{\mathrm{ij}}(\mathrm{u})$, called the genetic transfer rate, meets the conditions $\sum_{j=1}^{m} \psi_{i j}(u) \equiv 0, i=1, \ldots, m$; for any value of $u$. These conditions hold because of the absence of migrations into and mutations within the population. We assume absence of mutations because 
we are concerned with microevolution over human timescales (hundreds of years at most). By means of these functions, we have the following system of equations for genotype dynamics:

$$
\begin{aligned}
& d N / d t=N \vec{f}(N, u) \\
& d u_{i j} / d t=u_{i j}\left[f_{i j}(N)-\bar{f}(N, u)\right]+\psi_{i j}(u), i, j=1,2, \ldots, m .
\end{aligned}
$$

The allele frequency dynamics are therefore governed by

$$
\mathrm{dp}_{\mathrm{i}} / \mathrm{dt}=\sum_{\mathrm{j}=1}^{\mathrm{m}} \mathrm{du} u_{\mathrm{ij}} / d t=\overline{\mathrm{f}}_{\mathrm{i}}(\mathrm{N}, \mathrm{u})-\mathrm{p}_{\mathrm{i}} \overline{\mathrm{f}}(\mathrm{N}, \mathrm{u}), \mathrm{i}=1, \ldots, \mathrm{m},
$$

where $\bar{f}_{i}(N, u)=\sum^{m} u_{i j} f_{i j}(N)$ is the average per capita growth rate for the group of individuals $j=1$

carrying the ith allele in their genotypes. The per capita growth rates of the genotype groups are given by Equation 2.3, with the normalizing condition $\sum_{i=1}^{m} p_{i}=1$ automatically holding true.

In this mathematical model (Abrosov and Bogoliubov, 1985, 1988), the acting forces for the dynamics in the population genetic structure are variations in per capita growth rates of genotype group sizes. Equations (2.17) are formally coincident with the classical Fisher equations, whereas the dynamics of the allele frequencies alone are no longer sufficient to describe the dynamics of the genotype frequencies in diploid organisms. This circumstance has been stressed since publication of work of Kostitzin (1938), whose model shares many traits with Equations 2.16-2.17.

To evaluate the influence of vegetative reproduction on microevolution of a population, we must to make an important stipulation. Actually, the assumption that only one locus determines all the traits influencing the rates of sexual or vegetative reproduction, as well as the traits responsible for the rate of population decline, is far from realistic. Here we consider, therefore, only a few special cases: (1) nonclonal plants with selection on the sexual reproduction traits, (2) clonal plants capable of sexual reproduction with fixed seed output and selection on the vegetative reproduction traits, (3) clonal plants capable of sexual reproduction with selection on the sexual traits and fixed clonal spread, and, finally, (4) plants capable of only clonal spread. Comparison among these four cases will give some grounds for speculation on the possible effects of vegetative reproduction on microevolution of a given plant population. 
The analysis below is for the simplest (diallele), situation (i.e., for $m=2$ and $i, j=1,2$ ). Mutations and migrations are assumed to be absent in each case.

Case 1. Individuals of the population cannot reproduce vegetatively, no additional planting occurs after initial establishment, and the locus determines only the sexual reproduction traits. In other words,

$$
(i, j) \Rightarrow \alpha_{i j}>0, \gamma_{i j}=0, \beta_{i j}=\beta>0, i, j=1,2, \ldots m .
$$

In the diallele case $(m=2)$ it is convenient to use alternate variables. Because genotypes $(1,2)$ and $(2,1)$ are indistinguishable, $y=u_{12}=u_{21}$ corresponds to half of the heterozygote frequency, while $p=u_{11}+u_{12}$ gives the frequency of allele 1 (where $q=1-p$ shows the frequency of alternative allele 2). Equations 2.16-2.17 then take on the following form:

$$
\begin{aligned}
& \mathrm{dN} / \mathrm{dt}=[\bar{\alpha}(\mathrm{p}, \mathrm{y})-\beta \mathrm{N}] \mathrm{N}, \\
& \mathrm{dy} / \mathrm{dt}=\left[\alpha_{12}-\bar{\alpha}(\mathrm{p}, \mathrm{y})\right] \mathrm{y}+\psi(\mathrm{p}, \mathrm{y}), \\
& \mathrm{dp} / \mathrm{dt}=\bar{\alpha}_{1}(\mathrm{p}, \mathrm{y})-\mathrm{p} \bar{\alpha}(\mathrm{p}, \mathrm{y}),
\end{aligned}
$$

where

$$
\begin{aligned}
\bar{\alpha}(\mathrm{p}, \mathrm{y}) & =\alpha_{11} \mathrm{u}_{11}+2 \alpha_{12} \mathrm{u}_{12}+\alpha_{22} \mathrm{u}_{22} \\
& =\alpha_{11}(\mathrm{p}-\mathrm{y})+2 \alpha_{12} \mathrm{y}+\alpha_{22}(1-\mathrm{p}-\mathrm{y}) ; \\
\bar{\alpha}_{1}(\mathrm{p}, \mathrm{y}) & =\alpha_{11}(\mathrm{p}-\mathrm{y})+\alpha_{12} \mathrm{y} ; \\
\Psi(\mathrm{p}, \mathrm{y}) & =\frac{\alpha_{11} \alpha_{22}(\mathrm{p}-\mathrm{y})(1-\mathrm{p}-\mathrm{y})-\alpha_{12}^{2} \mathrm{y}^{2}}{\bar{\alpha}(\mathrm{p}, \mathrm{y})}
\end{aligned}
$$

In Equations 2.18 every population state is described by vector $Q=(p, y, N)$. Frequencies $p$ and y satisfy the following inequalities: $0 \leq p \leq 1,0 \leq y \leq 1 / 2$. Homozygote frequencies $\mathrm{u}_{11}=\mathrm{p}-\mathrm{y}$ and $\mathrm{u}_{22}=1-\mathrm{p}-\mathrm{y}$ are also nonnegative and do not exceed 1. Hence, $0 \leq \mathrm{p} \pm \mathrm{y} \leq 1$. Note that in this case equations for genetical structure dynamics are given separately from the equation for population density dynamics. 
Let us introduce the following designations:

$$
\begin{aligned}
& \sigma_{1}=\alpha_{12}-\alpha_{11} \\
& \sigma_{2}=\alpha_{12}-\alpha_{22}
\end{aligned}
$$

If at least some genotypes differ in their features responsible for sexual reproduction:

$$
\left|\sigma_{1}\right|+\left|\sigma_{2}\right|>0 \text {. }
$$

then in Equations 2.18 the following equilibrium monomorphic states exist:

$$
\begin{aligned}
& \mathrm{Q}_{11}=\left(1,0, \alpha_{11} / \beta\right) \\
& \mathrm{Q}_{22}=\left(0,0, \alpha_{22} / \beta\right)
\end{aligned}
$$

In state $\mathrm{Q}_{11}$, the population is represented exclusively by homozygotes $(1,1)$, for which $\mathrm{u}_{11}=1$. Hence, $p=1, y=0$, and $u_{22}=0$. The equilibrium population density is $N_{11}=\alpha_{11} / \beta$. At point $\mathrm{Q}_{22}$, the population consists entirely of homozygotes $(2,2)$, for which $\mathrm{u}_{22}=1 ; \mathrm{u}_{11}=0$, $q \geq 1-p \geq 1, y=0$. The population density $N$ corresponding to this monomorphic state is $\hat{\mathrm{N}}=\alpha_{22} / \beta$.

If the condition

$$
\sigma_{1} \sigma_{2}>0
$$

holds true, then the unique equilibrium genetic polymorphism is $\mathrm{Q}_{11}=\left(\hat{\mathrm{p}}, \hat{\mathrm{y}}, \hat{\mathrm{N}}_{12}\right)$. If the inequality 2.23 is violated, the population does not possess equilibrium genetic polymorphism. Allele frequencies at point $Q_{12}$ are equal to

$$
\begin{aligned}
& \hat{p}=\sigma_{2} /\left(\sigma_{1}+\sigma_{2}\right), \\
& \hat{\mathrm{q}}=\sigma_{1} /\left(\sigma_{1}+\sigma_{2}\right) . .
\end{aligned}
$$

Genotype frequencies comply with Hardy-Weinberg proportions

$$
\begin{aligned}
& \hat{y}=\hat{p} \hat{q} \\
& u_{11}=\hat{p}^{2} \\
& u_{22}=\hat{q}^{2}
\end{aligned}
$$

and population density $\mathrm{N}$ is given by

$$
\hat{\mathrm{N}}_{12}=\hat{\alpha} / \beta \text {. }
$$


Here $\hat{\alpha}=\bar{\alpha}(\hat{\mathrm{p}}, \hat{\mathrm{y}})$ denotes the average specific rate of sexual reproduction at the point of stationary genetic polymorphism:

$$
\hat{\alpha}=\alpha_{11} \hat{\mathrm{p}}^{2}+2 \alpha_{12} \hat{\mathrm{p}} \hat{\mathrm{q}}+\alpha_{22} \hat{\mathrm{q}}^{2} \text {. }
$$

If, beginning at some time value $t=t_{0}$, plants with different genotypes do not differ in their features, so that

$$
\sigma_{1}=0, \quad \sigma_{2}=0,
$$

or

$$
\alpha_{11}=\alpha_{12}=\alpha_{22}=\alpha,
$$

then allele frequencies in the population are constant:

$$
\mathrm{dp} / \mathrm{dt}=0 \text {. }
$$

At the same time, a genotype frequency change takes place in accordance with

$$
\mathrm{dy} / \mathrm{dt}=\alpha\left(\mathrm{p}_{\mathrm{o}} \mathrm{q}_{\mathrm{o}}-\mathrm{y}\right) \text {, }
$$

where $p_{o}$ and $q_{o}$ are allele frequencies when $t=t_{0}$. Accordingly, population density dynamics complies with the standard logistic equation,

$$
\mathrm{dN} / \mathrm{dt}=(\alpha-\beta \mathrm{N}) \mathrm{N} .
$$

Equations 2.29-2.31 have the solution:

$$
\begin{aligned}
& \mathrm{p}(\mathrm{t})=\mathrm{p}_{0}, \\
& \mathrm{y}(\mathrm{t})=\mathrm{p}_{\mathrm{o}} \mathrm{q}_{\mathrm{o}}+\left(\mathrm{p}_{\mathrm{o}} \mathrm{q}_{\mathrm{o}}-\mathrm{y}_{\mathrm{o}}\right) \mathrm{e}^{-\alpha\left(\mathrm{t}-\mathrm{t}_{\mathrm{o}}\right)}, \\
& \mathrm{N}(\mathrm{t})=\frac{\alpha}{\beta+\left(\alpha / \mathrm{N}_{\mathrm{o}}-\beta\right) \mathrm{e}^{-\alpha \mathrm{t}},}
\end{aligned}
$$

where $y_{0}$ is one-half of heterozygote frequency when $t=t_{0}, N_{0}=N\left(t_{0}\right)$. Thus, the equilibrium state of genetic variables $\hat{p}=p_{o}$, and $\hat{y}=p_{o} q_{o}$ is entirely determined by the initial allele frequency $p_{0}$, and one can speak about neutral dynamics of genetic variables and neutral selection.

Table 2.1 summarizes the existence conditions of equilibrium states $Q_{11}, Q_{12}, Q_{22}$ and of population neutral states and the eigenvalues corresponding to these states of characteristic 
equations. Monomorphic states $\mathrm{Q}_{\mathrm{ii}}, \mathrm{i}=1,2$ are asymptotically stable if $\sigma_{\mathrm{i}}<0, \alpha_{\mathrm{ii}}>0$ and unstable if $\sigma_{i}>0$. Genetic polymorphism $Q_{12}$ is asymptotically stable if $\sigma_{1}>0, \sigma_{2}>0$.

Parameter plane $\left(\sigma_{1}, \sigma_{2}\right)$ is divided into domains $E_{1}, E_{2}, E_{3}$, and $E_{4}$ (Fig. 2.1). In $E_{1}$, which is actually defined by

$$
\alpha_{11}>\alpha_{12}>\alpha_{22}
$$

state $Q_{11}$ is asymptotically stable, while state $Q_{22}$ is unstable. Because in this case $\hat{N}_{11}>\hat{N}_{22}$, one may say that a state is established at which the equilibrium population density is maximal. In $E_{3}$ the dynamic behavior is similar, except that state $Q_{22}$ is now asymptotically stable while state $Q_{11}$ is unstable, and $\hat{N}_{22}>\hat{N}_{11}$.

In domain $\mathrm{E}_{2}$ inequality 2.23 holds true and

$$
\alpha_{12}>\hat{\alpha}>\max \left\{\alpha_{11}, \alpha_{22}\right\}
$$

In this case the genetic polymorphism $\mathrm{Q}_{12}$ exists as an asymptotically stable node, whereas the monomorphic states $Q_{11}$ and $Q_{22}$ represent saddle points. The equilibrium population density meets the condition

$$
\hat{N}_{12}>\max \left\{\hat{N}_{11}, \hat{N}_{22}\right\} \text {. }
$$

In domain $\mathrm{E}_{4}$ the opposite inequality holds true:

$$
\alpha_{12}<\hat{\alpha}<\min \left\{\alpha_{11}, \alpha_{22}\right\}
$$

The unstable genetic polymorphism here is represented by a saddle point, whereas the monomorphic states are represented by stable nodes. Which of the states is eventually established depends exclusively on the initial state of the trajectory, and the eventual population density is not necessarily maximal. However, the population "escapes" the state $\mathrm{Q}_{12}$ of the least population density:

$$
\hat{N}_{12}<\min \left\{\hat{N}_{11}, \hat{N}_{22}\right\}
$$

Thus, a disruptive selection takes place in domain $\mathrm{E}_{4}$.

The above, rather standard, analysis of selection in the absence of vegetative reproduction provides a basis for comparison with three additional cases, which include vegetative reproduction. 
Case 2. In this case, plants are capable of both sexual and (various kinds of) vegetative reproduction, but the locus determines only the asexual reproduction traits. Hence,

$$
\begin{gathered}
\alpha_{\mathrm{ij}}=\alpha>0, \\
\gamma_{\mathrm{ij}}>0, \\
\beta_{\mathrm{ij}}=\beta>0, \\
i, j=1,2, m .
\end{gathered}
$$

Here the per capita growth rate of the group of individuals with genotype $(i, j), i, j=1,2$ is given by the function

$$
f_{i j}(N)=\alpha+\gamma_{i j}-\beta N \text {. }
$$

The average specific growth rate of the total population takes on the form

$$
\bar{f}(N, p, y)=\alpha+\bar{\gamma}(p, y)-\beta N,
$$

where

$$
\bar{\gamma}(\mathrm{p}, \mathrm{y})=\gamma_{11}(\mathrm{p}-\mathrm{y})+2 \gamma_{12} \mathrm{y}+\gamma_{22}(\mathrm{q}-\mathrm{y})
$$

is the average specific rate of asexual reproduction;

$$
\bar{\gamma}_{1}(\mathrm{p}, \mathrm{y})=\gamma_{11}(\mathrm{p}-\mathrm{y})+\gamma_{12} \mathrm{y}
$$

is the average specific rate of asexual reproduction among individuals carrying allele 1.

Since the genetic flow rate does not depend on asexual reproduction, it takes on the following form:

$$
\psi(\mathrm{p}, \mathrm{y})=\alpha(\mathrm{pq}-\mathrm{y})
$$

Finally, Equations 2.16-2.17 are transformed into

$$
\begin{aligned}
& \mathrm{dN} / \mathrm{dt}=[\alpha+\bar{\gamma}(\mathrm{p}, \mathrm{y})-\beta \mathrm{N}] \mathrm{N} \\
& \mathrm{dy} / \mathrm{dt}=\left[\gamma_{12}-\bar{\gamma}(\mathrm{p}, \mathrm{y})\right] \mathrm{y}+\alpha(\mathrm{p}(1-\mathrm{p})-\mathrm{y}) \\
& \mathrm{dp} / \mathrm{dt}=\bar{\gamma}_{1}(\mathrm{p}, \mathrm{y})-\mathrm{p} \bar{\gamma}(\mathrm{p}, \mathrm{y})
\end{aligned}
$$

If there are differences among genotypes in asexual reproduction specific rates,

$$
\left|\sigma_{1}\right|+\left|\sigma_{2}\right| \neq 0
$$


where $\sigma_{1}=\gamma_{12}-\gamma_{11}, \sigma_{2}=\gamma_{12}-\gamma_{22}$, then equilibrium monomorphic population states $\mathrm{Q}_{11}=\left(1,0, \hat{\mathrm{N}}_{11}\right)$ and $\mathrm{Q}_{22}=\left(0,0, \hat{\mathrm{N}}_{22}\right)$. exist. In its monomorphic states, the population density components are

$$
\mathrm{N}_{\mathrm{ii}}=\left(\alpha+\gamma_{\mathrm{ii}}\right) / \beta, \mathrm{i}=1,2 \text {. }
$$

If homozyotes $(1,1)$ exceed heterozyotes in asexual reproduction specific rate,

$$
\sigma_{1}=\gamma_{12}-\gamma_{11}<0
$$

and they are no more than slightly inferior to homozyotes $(2,2)$,

$$
\gamma_{22}-\gamma_{11}<\alpha,
$$

then the state $\mathrm{Q}_{11}$ is asymptotically stable. If one of the inequalities is true

$$
\sigma_{1}>0 \text { or } \gamma_{22}-\gamma_{11}>\alpha,
$$

then the state $Q_{11}$ is asymptotically unstable. Likewise, the state $Q_{22}$ is stable if

$$
\sigma_{2}<0, \text { and } \gamma_{11}-\gamma_{22}<\alpha
$$

and it is unstable if

$$
\sigma_{2}>0 \text { or } \gamma_{11}-\gamma_{22}>\alpha \text {. }
$$

For the equilibrium genetic polymorphism to exist, it is necessary and sufficient that either

$$
\sigma_{1}>0 \text { and } \sigma_{2}>0
$$

or

$$
\sigma_{1}<0 \text {, and } \sigma_{2}<0 \text {, and }\left|\sigma_{2}-\sigma_{1}\right|<\alpha
$$

holds true, where $\sigma_{\mathrm{i}}=\gamma_{12}-\gamma_{\mathrm{ii}}, \mathrm{i}=1,2$. This polymorphism is unique; its equilibrium values for the allele ( $p$ ) and genotype (y) frequencies can be finitely calculated (but are omitted here), because the Hardy-Weinberg relations are disturbed. The equilibrium density is given by $\hat{\mathrm{N}}_{12}=(\alpha+\hat{\gamma}) / \beta$, where $\bar{\gamma}(\hat{\mathrm{p}}, \hat{\mathrm{y}})$ is the average rate of asexual reproduction at the genetic polymorphism.

If Inequalities 2.51 is true, then polymorphism $Q_{12}$ is asymptotically stable. If Inequalities 2.52 is true, then polymorphism $\mathrm{Q}_{12}$ is asymptotically unstable. In domain $\mathrm{E}_{1}$ of the parameter plane (Figure 2.2), defined by inequalities

$$
\sigma_{1}<0,
$$




$$
\sigma_{2}>\min \left\{0, \alpha+\sigma_{1}\right\}
$$

there is no polymorphism, but only state $\mathrm{Q}_{11}$ is stable $\left(\mathrm{Q}_{22}\right.$ is unstable). In contrast with the previously studied case, the homozygotes $(2,2)$ are now permitted to be more adapted than the heterozygotes $\left(\sigma_{2}<0\right)$. Domain $E_{3}$ is defined by inequalities similar to Inequalities 2.53 (with $\sigma_{1}$ and $\sigma_{2}$ interchanged), and only state $Q_{22}$ is stable.

In domain $\mathrm{E}_{2}$, defined by Inequalities 2.51 , a unique genetic polymorphism, $\mathrm{Q}_{12}$, is stable. The homozygous states $\mathrm{Q}_{11}$ and $\mathrm{Q}_{22}$ are either saddle points or unstable nodes. Note that the inequalities $\gamma_{12}>\gamma^{*}>\max \left\{\gamma_{11}, \gamma_{22}\right\}$ hold true in domain $E_{2}$, so that

$$
\mathrm{N}_{12}^{*}>\max \left\{\mathrm{N}_{11}^{\mathrm{o}}, \mathrm{N}_{22}^{\mathrm{o}}\right\} \text {. }
$$

In domain $\mathrm{E}_{4}$, defined by Inequalities 2.52 , the unique equilibrium genetic polymorphism $\mathrm{Q}_{12}$ is unstable (saddle), while both homozygous states, $\mathrm{Q}_{11}$ and $\mathrm{Q}_{22}$, are stable nodes. That is, disruptive selection takes place. In addition, the inequalities

$$
\begin{aligned}
& N_{12}^{*}<\min \left\{N_{11}^{o}, N_{22}^{o}\right\}, \\
& I N_{11}^{o}-N_{22}^{O} \mid<\alpha / \beta
\end{aligned}
$$

hold in the domain.

Thus, if the locus determines the rate of asexual reproduction and is neutral with respect to other traits, then disruptive selection can occur if the heterozygote fitness (and population size) is the least. Another requirement for disruptive selection is that the densities at homozygous states $Q_{11}$ and $Q_{22}$ do not differ greatly. Otherwise, the final state is that at which the equilibrium density is maximal. Thus, the rate of asexual reproduction can influence the microevolution of the population.

Case 3. In this case plants are capable of both sexual and asexual reproduction, but the locus determines only the sexual reproduction traits. Moreover, in parallel with natural seed production, the planting or spread with cloned (or clonal) individuals takes place at a specific rate $\gamma$. In this case, the individuals are cloned from each genotype in proportion to its frequency in the population. Hence,

$$
(\mathrm{i}, \mathrm{j}) \Rightarrow \alpha_{\mathrm{ij}}
$$




$$
\begin{aligned}
& \gamma_{\mathrm{ij}}=\gamma>0, \\
& \beta_{\mathrm{ij}}=\beta, \\
& \mathrm{i}, \mathrm{j}=1,2, \ldots \mathrm{m} .
\end{aligned}
$$

Case 3 can actually be reduced to Equations 2.18 , with the equation for the density (Equation 2.18a) being transformed into $d N / d t=[\bar{\alpha}(p, y)+\gamma-\beta N] N$ and the equations for the genetic structure dynamics (Equations $2.18 \mathrm{~b}$ and $2.18 \mathrm{c}$ ) being unchanged. Consequently, neither the rate of vegetative reproduction nor that of cloning will influence microevolution of the population, yet both may increase the total population density.

Case 4. In this case, we assume that the population of plants has lost its capability for sexual reproduction (e.g., due to the disappearance of pollinators). Then, for any genotype $(i, j)$, $\alpha_{\mathrm{ij}}=0, \mathrm{i} \leq \mathrm{j}=1, \ldots, \mathrm{m}$. The plants are capable of vegetative reproduction with the rate dependent on the genotype, and self-regulation rates, $\beta_{\mathrm{ij}}$, are genotype dependent. Hence,

$$
\begin{aligned}
& (\mathrm{i}, \mathrm{j}) \Rightarrow \alpha_{\mathrm{ij}}=0, \\
& \gamma_{\mathrm{ij}}>0, \\
& \beta_{\mathrm{ij}}>0, \\
& \mathrm{i}, \mathrm{j}=1,2, \ldots \mathrm{m} .
\end{aligned}
$$

In this case the genetic flow rate $\psi_{\mathrm{ij}}(\mathrm{u})$ is zero for any genotype (i,j). From Equation 2.12. it follows that the dynamics of genotype group sizes $\mathrm{N}_{\mathrm{ij}}$ obey the following:

$$
d N_{i j} / d t=f_{i j}(N) N_{i j}, \quad i \leq j=1,2
$$

Here

$$
f_{i j}(N)=\gamma_{i j}-\beta_{i j} N,
$$

where

$$
\mathrm{N}=\mathrm{N}_{11}+2 \mathrm{~N}_{12}+\mathrm{N}_{22}
$$

(Notation $\mathrm{N}_{12}$ indicates the population size of heterozygotes rather than half the size as in eariier cases.

Three equilibrium states $N=\left(N_{11}, 2 N_{12}, N_{22}\right)$ are possible in Equations 2.58:

$$
N_{11}=\left(\gamma_{11} / \beta_{11}, 0,0\right)
$$


in which the population consists exclusively of homozygotes $(1,1)$, and the equilibrium frequency of allele 1 is equal to 1 ;

$$
N_{12}=\left(0, \gamma_{12} / \beta_{12}, 0\right)
$$

in which the population consists exclusively of heterozygotes, and the equilibrium frequencies of alleles 1 and 2 are equal to $1 / 2$; and

$$
N_{22}=\left(0,0, \gamma_{22} / \beta_{22}\right)
$$

in which the population consists exclusively of homozygotes $(2,2)$, and the equilibrium frequency of allele 2 is equal to 1.

Let the genotypes be different in their fitnesses $\gamma_{\mathrm{ij}} / \beta_{\mathrm{ij}}$. An equilibrium state $N_{i j}$ will be locally stable if

$$
\gamma_{\mathrm{ij}} / \beta_{\mathrm{ij}}=\max _{\mathrm{k}, \mathrm{l}}\left\{\gamma_{\mathrm{k} l} / \beta_{\mathrm{k} l}\right\}=\max \left\{\gamma_{11} / \beta_{11}, \gamma_{12} / \beta_{12}, \gamma_{22} / \beta_{22}\right\}
$$

If, on the other hand, $\gamma_{\mathrm{ij}} / \beta_{\mathrm{ij}}=\min \left\{\gamma_{11} / \beta_{11}, \gamma_{12} / \beta_{12}, \gamma_{22} / \beta_{22}\right\}$, then the equilibrium state $N_{i j}$ is locally unstable.

Thus, if genotypes $(1,1),(1,2)$, and $(2,2)$ are different in their fitnesses $\gamma_{\mathrm{ij}} / \beta_{\mathrm{ij}}$, then the population possesses a unique locally stable equilibrium, at which the fitness attains its maximum value. Figure 2.3 shows the structural portrait of Equations 2.58 in the plane of parameters $\left(\varepsilon_{1}, \varepsilon_{2}\right)$, where

$$
\varepsilon_{\mathrm{i}}=\gamma_{12} / \beta_{12}-\gamma_{\mathrm{ii}} / \beta_{\mathrm{ii}}, \quad \mathrm{i}=1,2 \text {. }
$$

Comparison of this portrait with those of Cases 1 and 2, where a positive rate of sexual reproduction was supposed, is useful.

The inequalities that determine the domain $\Omega_{12}=\left\{\left(\varepsilon_{1}, \varepsilon_{2}\right): \varepsilon_{1}>0, \varepsilon_{2}>0\right\}$ are obviously equivalent to the condition that

$$
\gamma_{12} / \beta_{12}>\max \left\{\gamma_{11} / \beta_{11}, \gamma_{22} / \beta_{22}\right\}
$$

Hence, in domain $\Omega_{12}$ the sole locally stable equilibrium is the state in which only heterozygotes survive. No phenotypic diversity is expected in this state, but the allele frequencies are both nonzero (equal to $1 / 2$ ). In this sense, we may still speak of genetic polymorphism, perhaps better 
called allele polymorphism in this case. The distinction between these two terms disappears in the Fisher approach to genetic dynamics.

In domain $\left.\Omega_{11}=\left\{\varepsilon_{1}, \varepsilon_{2}\right): \varepsilon_{1}<0, \varepsilon_{2}>\varepsilon_{1}\right\}$ the condition

$$
\gamma_{11} / \beta_{11}>\max \left\{\gamma_{12} / \beta_{12}, \gamma_{22} / \beta_{22}\right\}
$$

obviously holds true, where the locally stable state is that in which only homozygotes $(1,1)$ survive. Of course, neither phenotypic diversity nor genetic polymorphism nor allele polymorphism can be observed in this state.

Similarly, in domain $\Omega_{22}=\left\{\left(\varepsilon_{1}, \varepsilon_{2}\right): \varepsilon_{1}<\varepsilon_{2}, \varepsilon_{2}<0\right\}$, we have

$$
\gamma_{22} / \beta_{22}>\max \left\{\gamma_{12} / \beta_{12}, \gamma_{12} / \beta_{12}\right\},
$$

whereby the locally stable state is the state in which only homozygotes $(2,2)$ survive. Again, neither phenotypic diversity nor genetic polymorphism nor allelic polymorphism can be observed in this state. Thus, when a plant population loses the ability to reproduce sexually, its phenotypic and genotypic diversity are expected to decrease.

If plant genotypes differ in sexual reproduction traits and are alike in their ability to reproduce vegetatively (Case 1 and Case 3), then the population-genetics mechanism for maintenance of stable polymorphism is overdominance. If the fitness of the heterozygotes is inferior to that of the two homozygotes, then an unstable polymorphism exists, the outcomes of intraspecific competition depend on the initial genotype frequencies, and selection acquires a distuptive character.

When, on the contrary, genotypes differ only in their vegetative reproduction features and have the same abilities for sexual reproduction (Case 2), then, in case of superior heterozygote fitness (see $E_{2}$ in Figure 2.2), a stable polymorphism is established. However, in Case 2 the inferior heterozygote fitness is not enough to establish disruptive selection. In addition, rather small homozygote differences are required (see $\mathrm{E}_{4}$ in Figure 2.2). The sexual reproductive rate acts as the measure of these differences. Thus, we can conclude that the differential ability of genotypes for vegetative reproduction influences population microevolution. Such a conclusion 
is supported by a comparison of genetic frequency dynamics in Case 2 and that in the case of neutral selection.

Let us assume that all conditions of Case 2 are observed and that we increase the specific rate of sexual reproduction, $\alpha$, for example by fertilization. If heterozygotes possess inferior fitness, then under a sufficiently low sexual reproduction rate, $\alpha<\left|\sigma_{2}-\sigma_{1}\right|$, only one of the monomorphic states will be stable (Figure 2.4). When the specific rate of sexual reproduction exceeds $\left|\sigma_{2}-\sigma_{1}\right|$, the population acquires one more monomorphic stable state, and the microevolution of a given population can proceed in the direction opposite that prevailing at low values of $\alpha$.

Let us assume that by restoring the plant's habitat we intensify its vegetative reproduction (e.g., by irrigating). If, against genotypic response to the change of habitat, at least one of the deviations $\sigma_{\mathrm{i}}=\gamma_{12}-\gamma_{\mathrm{ii}}$ has its sign changed to negative, then selection changes direction. If signs of deviations remain constant in the course of habitat restoration and we are confident that heterozygote fitnesses are not the worst,

$$
\gamma_{12}>\min \left\{\gamma_{11}, \gamma_{22}\right\}
$$

then changes of the environment will not affect the direction of microevolution.

If the intensities of a genotype's vegetative reproduction, $\gamma_{\mathrm{ij}}$, multiplicatively depend on some two positive parameters $\gamma_{o}$ and $\omega_{i j}: \gamma_{i j}=\gamma_{o} \omega_{i j}$ and if parameters $w_{i j}$ are constant during these environmental changes, then the sign of deviations $\sigma_{i}=\gamma_{o}\left(\omega_{12}-\omega_{i i}\right), \mathrm{i}=1,2$, is preserved. The parameter $\gamma_{0}$ can change along the gradient of habitat changes. When heterozygote fitness is inferior, an increase in the intensity of vegetative reproduction can lead to a loss of unstable equilibrium polymorphism and to a change in the direction of population microevolution. In particular, when vegetative reproduction intensity is low, $\gamma_{0}<\alpha /\left|\omega_{11}-\omega_{22}\right|$, the population possesses two stable monomorphic states $Q_{11}$ and $Q_{22}$ (Figure 2.5). An increase in the intensity of vegetative reproduction can lead to the disappearance of unstable polymorphisms and to the destabilization of one of the monomorphic 
states, causing the plant population to possess only the stable state (Figure 2.5). As a result of this influence the direction of the population's microevolution can change.

Let the specific rate of vegetative reproduction be additively and not multiplicatively dependent on two parameters: $\gamma_{i j}=\gamma_{o}+\omega_{i j}$. Then parameters $\omega_{\mathrm{ij}}$ are independent of habitat changes, and the increase in intensity of vegetative reproduction at the expense of parameter $\gamma_{0}$ can affect only the microevolution rate, not the selection direction. Thus, if traits responsible for asexual reproduction are genetically determinated, the rate of asexual reproduction can influence the microevolutionary process.

In a steady environment, a complete loss of sexual reproduction, on a background of vegetative renewal and subject to differences in the fitness of genotypes, would cause a population to have the locally stable equilibrium at which the greatest fitness is attained. The population would be represented only by the bearers of the most fit genotype, and no genotypic (hence phenotypic) diversity would be observed unless only heterozygotes survived. Thus, for a population of plants lacking sexual reproduction, the genetic and phenetic diversity would probably correlate with the diversity of habitat conditions.

We often worry about decreases in plant populations. The introduction of seed mixtures and transplantation of propagules to restored habitats are commonly used to increase plant populations. However, these methods of supporting plant populations may well affect their microevolution. The analysis of Cases 2 and 3 showed that some methods for increasing population density do not affect the direction of microevolution. Indeed, let us assume that we annually introduce propagules at a rate $\mathrm{A}(\mathrm{t})$ that is proportional to the current population density: $A(t)=\kappa N(t)$. When the frequencies $v_{i j}(t)$ of genotypes $(i, j)$ of introduced seeds coincide with the current frequencies of the population genotypes, so that $v_{\mathrm{ij}}(\mathrm{t})=\mathrm{u}_{\mathrm{ij}}(\mathrm{t})$, then the introduction rate of each genotype $(i, j)$ is equal to $\kappa_{0} u_{i j}(t)$, and coefficient $\kappa_{0}$ does not depend on the genotype. This coefficient is analogous to the specific rate of vegetative reproduction or to some additive component of this rate. In this way, if we annually introduce plants seeds for habitat restoration 
with due consideration for the population's genetic variability, we do interfere with its microevolution.

Is our current practice of maintaining plant population size linked to an analysis of its genetic variability? Does not the neglect of genetic and phenotypic variability of plant populations contradict our desire to increase, maintain, or restore the abundance of populations?

\section{MICROEVOLUTION IN RESPONSE TO NEW HABITATS}

If the genetic structure of a plant population may change along "physiographic gradients," then it should change when plants are transplanted. Relevant to this case is an ecogenetic model [Bogoliubov and Abrosov, 1985] of intraspecies trophic competition among genotypes for limiting resources like the nutrients nitrogen, phosphorus, and potassium. We will show that variations in the per capita rate of plant elimination or in the resource inflow rate may cause changes in the population genetic structure. The variations in the per capita rate of plant elimination can be related, for instance, to those variations in the temperature of the habitat.

Suppose that the specific rate of sexual reproduction for individuals of any genotype $(\mathrm{i}, \mathrm{j})$ as a function of the resource concentration, $\left.S \mathrm{~g} / \mathrm{m}^{2}\right): \mu_{\mathrm{ij}}=\mu_{\mathrm{ij}}(\mathrm{S})$, and the biomass, $\mathrm{X}_{\mathrm{ij}}\left(\mathrm{g} / \mathrm{m}^{2}\right)$, of genotype $(i, j)$ individuals, is proportional to the population density $N_{i j}$ (individuals $/ \mathrm{m}^{2}$ ). Then, in the case of a diallele locus, the equations for the dynamics of the ecogenetic structure (i.e., the allele and genotype frequencies combined with the total biomass) of an isogamic, panmictic population of plants take on the following form:

$$
\begin{aligned}
& \mathrm{dp} / \mathrm{dt}=\overline{\mathrm{f}}_{1}(S, p, y)-\mathrm{p} \overline{\mathrm{f}}(\mathrm{S}, \mathrm{p}, \mathrm{y}) \\
& \mathrm{dy} / \mathrm{dt}=\mathrm{y} \bar{\delta}(S, p, y)+\psi(S, p, y) \\
& \mathrm{dX} / \mathrm{dt}=[\bar{\mu}(S, p, y)-\bar{\rho}(p, y)] X \\
& \mathrm{dS} / \mathrm{dt}=\mathrm{R}-\mathrm{DS}-\bar{\varphi}(S, p, y) X
\end{aligned}
$$

Here $\mathrm{p}$ is the frequency of allele $1 ; \mathrm{y}$ is a half of the heterozygote frequency; $\mathrm{X}$ is the totai

population biomass; $\mathrm{R}\left(\mathrm{g} /\left[\mathrm{m}^{2} \cdot\right.\right.$ day $\left.]\right)$ is a constant resource inflow, and $\mathrm{D}\left(\right.$ day $\left.{ }^{-1}\right)$ is the rate of resource decay and/or outflow by all means, except for uptake by plants. 
Let also $q=1-p$ denote the frequency of allele $2, u_{11}=p-y$ that of homozygotes $(1,1)$, and $\mathrm{u}_{22}=\mathrm{q}-\mathrm{y}$ that of homozygotes $(2,2)$. Then

$$
\begin{aligned}
& \bar{\mu}(S, p, y)=\mu_{11}(S) u_{11}+2 \mu_{12}(S) y+\mu_{22}(S) u_{22}, \\
& \bar{\rho}(p, y)=\rho_{11} u_{11}+2 p_{12} y+\rho_{22} u_{22}
\end{aligned}
$$

represent the per capita rates of population growth and mortality averaged over the genotypes, with $\rho_{i j}(i, j=1,2)$ denoting the specific rate of elimination of genotype $(i, j)$ individuals. Function

$$
f_{i j}(S)=\mu_{i j}-\rho_{i j}
$$

represents the specific growth rate for the biomass of genotype $(i, j)$ individuals, and

$$
\bar{f}_{i}(S, p, y)=f_{i i}(S) u_{i i}+f_{12}(S) y
$$

is the average specific growth rate for the biomass of individuals bearing allele $i(i=1,2)$. Therefore,

$$
\bar{f}(S, p, y)=\bar{f}_{1}(S, p, y) p+\bar{f}_{2}(S, p, y) q
$$

is the averaged specific growth rate of the total population biomass.

Function

$$
\bar{\delta}(S, p, y)=\bar{f}_{12}(S)-\bar{f}(S, p, y)
$$

represents the difference between the specific heterozygote rate of growth and the average specific growth rate of the total biomass. Function

$$
\bar{\varphi}(S, p, y)=\varphi_{11}(S) u_{11}+2 \varphi_{12}(S) y+\varphi_{22}(S) u_{22}
$$

represents the average rate of resource uptake by a unit biomass of the total population, where $\varphi_{\mathrm{ij}}(\mathrm{S})$ is the specific rate of resource uptake by plants of genotype $(\mathrm{i}, \mathrm{j})$.

Function $\psi(S, p, y)$, the genetic flow rate, can be reduced to the following form:

$$
\psi(S, p, y)=\bar{\mu}_{1}(S, p, y) \bar{\mu}_{2}(S, p, y) / \bar{\mu}(S, p, y)-\mu_{12}(S) y
$$

Here

$$
\bar{\mu}_{\mathrm{i}}(\mathrm{S}, \mathrm{p}, \mathrm{y})=\mu_{\mathrm{ii}}(\mathrm{S}) \mathrm{u}_{\mathrm{ii}}+\mu_{12}(\mathrm{~S}) \mathrm{y}
$$

is the average specific reproduction rate of plants possessing allele $i$ in their genotype.

We further assume that the genotype-specific growth rates are proportional to the respective rates of resource uptake: 


$$
\mu_{\mathrm{ij}}(\mathrm{S})=\gamma \varphi_{\mathrm{ij}}(\mathrm{S}) .
$$

Here the genotype-invariant, dimensionless coefficient $\gamma$ is the efficiency of converting the resource into plant biomass.

The following discussion focuses on the case where the locus determines only the reproduction rate and is neutral with respect to traits that determine the rates of elimination; hence, $\rho_{i j}=\rho, i, j=1,2$. Equation 3.14 shows that this is equivalent to the case where the locus determines the rate of resource uptake. The system of Equations 3.1-3.4 and 3.14 then takes on the following form (Bogoliubov and Abrosov, 1985; Bogoliubov et al., 1986):

$$
\begin{aligned}
& \mathrm{dp} / \mathrm{dt}=\bar{\mu}_{1}-\mathrm{p} \bar{\mu} \\
& \mathrm{dy} / \mathrm{dt}=\bar{\mu}_{1} \bar{\mu}_{2} / \bar{\mu}-\bar{\mu} \\
& \mathrm{dX} / \mathrm{dt}=[\bar{\mu}-\rho] \mathrm{X} \\
& \mathrm{dS} / \mathrm{dt}=\mathrm{R}-\mathrm{DS}-\bar{\mu} \mathrm{X} / \gamma
\end{aligned}
$$

Here the terms denoted by letters $\mu$ are actually functions of (S,p,y) as before, with the following qualitative constraints: their constituent functions $\mu_{\mathrm{ij}}(\mathrm{S})$ are monotone, increasing from zero up to respective saturation levels and

$$
\lim _{S \rightarrow \infty} \mu_{i j}(S)=\alpha_{i j}>0, i, j=1,2 .
$$

In pure ecological models like Equations 3.17-3.18, which neglect population genetic processes, a unique, nontrivial equilibrium state may exist, whose existence and stability depend on the resource inflow rate $R$ and the specific elimination rate $p$. In the system of Equations 3.153.18 , however, the dynamics of genetic variables $p$ and $y$ depend on the resource concentration $S$. The dynamics of the population biomass $\mathrm{X}$ and the limiting resource concentration $\mathrm{S}$ are, in turn, not separated from the population genetic characteristics. Therefore, each equilibrium state in the genetic variables corresponds to a certain state in the ecologic variables $\mathrm{S}$ and $\mathrm{X}$. The discussion below shows that the set of feasible equilibrium states for the latter model is expanded over that for a common ecologic model like Equations 3.17-3.18. 
Let the subset of genetic variables be designated by vector $\Gamma=(p, y)$ and the subset of ecologic variables by vector $\mathbf{H}=(\mathrm{X}, \mathrm{S})$. The following equilibrium states are possible in terms of $\Gamma$ :

$$
\begin{aligned}
& \Gamma_{11}=(1,0), \text { where } q=0, u_{11}=1, u_{22}=0 \\
& \Gamma_{22}=(0,0), \text { where } q=1, u_{11}=0, u_{22}=1 ; \\
& \Gamma_{12}=\left(p^{*}, y^{*}\right) \in \Omega
\end{aligned}
$$

In Equation 3.22, $\mathrm{p}^{*}$ and $\mathrm{y}^{*}$ are equilibrium values for the frequencies $\mathrm{p}$ and $\mathrm{y}$, while the domain is defined as $\Omega=\{(p, y) \mid p, 2 y, p \pm y \in(0,1)\}$.

A stationary biomass $\mathrm{X}_{\mathrm{ij}}$ and a limiting resource concentration $\mathrm{S}_{\mathrm{ij}}$ correspond to each of the genetic equilibria $\Gamma_{i j}$, forming the ecologic equilibrium states $H_{i j}=\left(X_{i j}, S_{i j}\right)$. Equilibrium values for the biomass are given by

$$
X_{i j}=\gamma\left(R-D S_{i j}\right) / \rho,
$$

while the equilibrium resource concentration $S_{\mathrm{ij}}$ obeys the equation

$$
\bar{\mu}\left(\Gamma_{\mathrm{ij}}, S_{\mathrm{ij}}\right)=\rho .
$$

For monomorphic $(i=j)$ states, Equation 3.24 takes on the form $\mu_{\mathrm{ii}}(S)=\rho$, which has, by virtue of constraints on the function $\mu$, a unique positive solution if and only if $\rho<\alpha_{\mathrm{ii}}$. For the case of genetic polymorphism $\Gamma_{12}$, the equilibrium values of the allele frequency $\mathrm{p}^{*}$ and heterozygote frequency $2 y^{*}$ depend on $S_{12}(\rho)$ and are given by the expressions

$$
\mathrm{p}^{*}=\frac{\sigma_{2}(S)}{\sigma_{1}(S)+\sigma_{2}(S)}, \mathrm{q}^{*}=1-\mathrm{p}^{*}, \mathrm{y}^{*}=\mathrm{p}^{*} \mathrm{q}^{*}
$$

where $\sigma_{\mathrm{i}}=\mu_{12}(\mathrm{~S})-\mu_{\mathrm{ii}}(\mathrm{S}),(\mathrm{i}=1,2)$ designate the deviation functions. The polymorphic equilibrium concentration $S_{12}(\rho)$ obeys the equation

$$
\mu_{11}(S) \mu_{22}(S)-\mu_{12}^{2}(S)+\rho\left[\sigma_{1}(S)+\sigma_{2}(S)\right]=0 .
$$

Finally, the polymorphic ecogenetic equilibrium state should meet the system of Equations 3.23 and 3.25-3.26. The system can be shown to have no feasible solutions if the parameter $\rho$ is large enough. However, if $\rho$ is sufficiently small, a unique positive solution exists. 
We'll say that the equilibrium ecogenetic state $\left(\Gamma_{\mathrm{ij}}, \mathrm{H}_{\mathrm{ij}}\right)$ does exist if $\mathrm{X}_{\mathrm{ij}}>0, \mathrm{~S}_{\mathrm{ij}}>0$ and $\Gamma_{\mathrm{ij}} \in \Omega$ $U \partial \Omega$ where $\partial \Omega$ denotes the boundary of $\Omega$. From expression (3.23) it follows that for the existence of ecogenetic state $\left(\Gamma_{\mathrm{ij}}, \mathrm{H}_{\mathrm{ij}}\right)$ the following conditions must be observed

$$
0<S_{i j}(\rho)<R / D
$$

If a given ecogenetic state $\left(\Gamma_{\mathrm{ij}}, \mathrm{H}_{\mathrm{ij}}\right)$ does exist, then its local stability is completely determined by the signs of the deviation functions $\sigma_{k}\left(S_{12}\right),(k=1,2)$ at this state. A monomorphic ecogenetic state $\left(\Gamma_{\mathrm{ii}}, \mathrm{H}_{\mathrm{ii}}\right)$ will be locally stable if the specific growth rate of homozygotes $(i, i)$ exceeds that of heterozygotes:

$$
\mu_{\mathrm{ii}}\left(\mathrm{S}_{\mathrm{ii}}\right)>\mu_{12}\left(\mathrm{~S}_{\mathrm{ii}}\right)
$$

The polymorphic ecogenetic state $\left(\Gamma_{12}, \mathrm{H}_{12}\right)$ will be locally stable if the specific growth rates of heterozygotes exceed those of homozygotes:

$$
\mu_{12}\left(S_{12}\right)>\mu_{\mathrm{ii}}\left(S_{12}\right), \mathrm{i}=1,2 \text {. }
$$

If the polymorphic ecogenetic state $\left(\Gamma_{12}, \mathrm{H}_{12}\right)$ exists and the inequalities

$$
\sigma_{\mathrm{k}}\left(\mathrm{S}_{12}\right)<0, \mathrm{k}=1,2
$$

hold true, these being equivalent to

$$
\mu_{12}\left(S_{12}\right)<\mu_{\mathrm{kk}}\left(S_{12}\right), k=1,2,
$$

then the polymorphic state is locally unstable, appearing to be a saddle point.

Thus, for a monomorphic state $\left(\boldsymbol{\Gamma}_{\mathrm{ii}}, \mathrm{H}_{\mathrm{ii}}\right)$ of the population to be (locally Lyapunov) stable (or unstable) under the limiting-resource concentration $S=S_{i i}$, the specific growth rate, $\mu_{\mathrm{ii}}$, of homozygotes (i,i) must be greater (or less) than that of heterozygotes, $\mu_{12}$. The polymorphic state ( $\Gamma_{12}, \mathrm{H}_{12}$ ) will be stable (or unstable), under the concentration $S=S_{12}$, if the specific growth rate, $\mu_{12}$, of heterozygotes is greater (or less) than any of those, $\mu_{\mathrm{ii}}$, of homozygotes $(\mathrm{i}, \mathrm{i})$, $\mathrm{i}=1,2$. The stability conditions for the polymorphic state cannot occur simultaneously with those for any of the monomorphic states.

The set of equations 3.15-3.18 formally has the following stationary solutions:

$$
X=0, S=R / D,(p, y)=\Gamma_{i j}
$$


where $\Gamma_{\mathrm{ij}}$ is determined by expressions $3.20-3.22$ and 3.25. If $S_{\mathrm{ij}}(\rho)>R / D$ holds true then the states (3.32) are locally stable. If at least one ecogenetic state $\left(\Gamma_{\mathrm{ii}}, \mathrm{H}_{\mathrm{ii}}\right)$ exists then the given stationary solutions (3.32) are locally unstable.

If, for a given ecogenetic equilibrium $\left(\Gamma_{\mathrm{ij}}, \mathrm{H}_{\mathrm{ij}}\right), \mathrm{i}, \mathrm{j}=1,2$, the existence conditions hold true and if, for the given habitat conditions $\mathrm{D}$ and $\mathrm{R}$, the corresponding biomass value, $\mathrm{X}_{\mathrm{ij}}$, meets the condition

$$
\mathrm{X}_{\mathrm{ij}}=\max _{\mathrm{k}, \mathrm{l}}\left\{\mathrm{X}_{\mathrm{k} l} \mid \exists\left(\Gamma_{\mathrm{k} l}, \mathbf{H}_{\mathrm{k} t}\right)\right\},
$$

then the state $\left(\Gamma_{\mathrm{ij}}, \mathrm{H}_{\mathrm{ij}}\right)$ is stable. In particular, if only one equilibrium state $\left(\Gamma_{\mathrm{ij}}, \mathbf{H}_{\mathrm{ij}}\right)$ exists, then it is necessarily stable. Loosely speaking, one may say that the preferable steady states are those at which the highest values of the total population biomass are observed.

From expression (3.23) it follows that the condition (3.35) is equivalent to

$$
\mathrm{S}_{\mathrm{ij}}=\min _{\mathrm{k}, \mathrm{l}}\left\{\mathrm{S}_{\mathrm{k} l} \mid \exists\left(\boldsymbol{\Gamma}_{\mathbf{k} l}, \mathbf{H}_{\mathrm{k} l}\right)\right\} \text {, }
$$

which states that the resources are reduced to a minimum. Extremal properties of ecosystem steady states have been discussed extensively in the literature on theoretical ecology (see, for example, Svirezhev and Logofet, 1983; Logofet, 1993, Ch.7.IV; and references therein). Conditions (3.35) and (3.36), being sufficient for the ecogenetic structure, $\left(\Gamma_{\mathrm{ij}}, \mathrm{H}_{\mathrm{ij}}\right)$, of a population to be stable, are in remarkable agreement with similar properties formulated for the whole ecosystem, without accounting for the population genetic properties.

For some habitat conditions, the set of ecogenetic population states include some stable and some unstable states. The set of equilibrium ecogenetic states of a population that are feasible for given habitat conditions is called the spectrum of ecogenetic states (EG-spectrum) of the population. Changing the parameters R, D or $\rho$ in Equations 3.15-3.18 may result in bifurcations of an equilibrium state and hence in modifications of its EG spectrum. Depending on the pattern of behavior of the deviation functions relative to each other and on the habitat conditions $\mathrm{D}$ and $\mathrm{R}$, the following kinds of EG spectra are possible:

$A_{i i i}$ Both of the monomorphic states exist but no polymorphic state. The monomorphic state $\left(\Gamma_{\mathrm{ii}}, \mathrm{H}_{\mathrm{ii}}\right)$ is stable, while the alternative state, $\left(\Gamma_{\mathrm{jj}}, \mathrm{H}_{\mathrm{jj}}\right)$, is unstable, and $\mathrm{i}, \mathrm{j}=1,2, \mathrm{i} \neq \mathrm{j}$. 
$A_{12}^{+}$: A polymorphic state $\left(\Gamma_{12}, \mathrm{H}_{12}\right)$ and both of the monomorphic states are all stable.

$A_{12}$ : The polymorphic state $\left(\Gamma_{12}, \mathrm{H}_{12}\right)$ exists but is unstable, while both monomorphic states are stable.

$\mathrm{B}_{12}^{\mathrm{ii}}$ : A stable polymorphic state $\left(\Gamma_{12}, \mathrm{H}_{12}\right)$ and an unstable monomorphic state $\left(\Gamma_{\mathrm{ii}}, \mathbf{H}_{\mathrm{ii}}\right)$ exist, not an alternative monomorphic state $\left(\Gamma_{\mathrm{j} j}, \mathrm{H}_{\mathrm{jj}}\right)$, where $\mathrm{i}, \mathrm{j}=1,2, \mathrm{i} \neq \mathrm{j}$,

$B_{22}^{11}$ : Both monomorphic states, $\left(\Gamma_{11}, H_{11}\right)$ and $\left(\Gamma_{22}, H_{22}\right)$, are stable, but genetic polymorphic state does not exist.

$C_{i j}$ : The only existing state $\left(\Gamma_{\mathrm{ij}}, \mathbf{H}_{\mathrm{ij}}\right), \mathrm{i}, \mathrm{j}=1,2$, is stable.

All the spectra are summarized, in terms of their existence and (local) stability, in Table 3.1.

The EG spectra of the A types imply the obligatory existence of monomorphic states. In addition, disruptive dynamics of the genetic variables take place in type A structures only if an unstable genetic polymorphism $\left(\boldsymbol{\Gamma}_{12}, \mathbf{H}_{12}\right)$ exists. The situation is similar to the Fisher-WrightHaldane models and the logistic ecogenetic model (Equation 2.2).

By virtue of Equations 3.15-3.18, the dynamics of genetic frequencies depend on changes in the limiting-resource concentration. Therefore, the EG spectra of the B types arise. These are characterized by the lack of one of the monomorphic states. EG spectra of the $\mathrm{C}$ type possess only one equilibrium state. Spectrum $\mathrm{B}_{22}^{11}$ is interesting in that it corresponds to the conditions of disruptive selection because it lacks genetic polymorphism not because it is unstable.

The existence and stability of steady ecogenetic states are determined by the signs of the deviation functions $\sigma_{i}(S), i=1,2$, defined in Equation 3.27 and calculated at the given equilibrium point. The pattern of changes in the ecogenetic structure, and hence the policy to control, then is therefore dependent on behavior of those deviation functions. Figure 3.1 shows possible patterns of the behavior, under the condition that each of the equations

$$
\sigma_{\mathrm{k}}(\mathrm{S})=0, \mathrm{k}=1,2,
$$

has no more than one positive solution, which we denote by $c_{k}, k=1,2$.

Equilibrium resources concentrations $S_{\mathrm{ij}}(\rho)$ are monotone increasing functions of the specific elimination rate. Hence, the change of specific elimination rate can lead to the alternation 
of sign of deviation functions $\sigma_{1}(\mathrm{~s})$ and $\sigma_{2}(\mathrm{~s})$. Values $\rho=\mathrm{d}_{\mathrm{k}}$ under which the alternation of deviation functions sign takes place, satisfy the equation:

$$
\mathrm{S}_{\mathrm{kk}}\left(\mathrm{d}_{\mathrm{k}}\right)=\mathrm{c}_{\mathrm{k}} \text {, }
$$

$k=1,2$. In other words $\mu_{\mathrm{kk}}\left(c_{\mathrm{k}}\right)=\mathrm{d}_{\mathrm{k}}$. The equilibrium biomass and resource concentration must be positive. Hence, in accordance with (3.23) equilibrium concentration values must be less than R/D. Thus, for the ecogenetic state $\left(\mathrm{p}_{\mathrm{ij}}, \mathrm{H}_{\mathrm{ij}}\right)$ to be able to exist specific elimination rate must be less than certain value $b_{i j}$ which satisfies the equation:

$S_{i j}\left(b_{i j}\right)=R / D$.

Because the equilibrium biomass and resource concentration must be positive, Equation 3.36 makes sense only when $c_{k}<R / D$.

At any sufficiently small $\rho$ a population is characterized by a certain spectrum of ecogenetic states. Increasing $\rho$ we can exceed one of the bifurcation values $d_{1}$ and $d_{2}$. For the deviation functions of the III and IV type $\sigma_{1}(s)$ or $\sigma_{2}(s)$ the value $d_{k}$ does exist and of the I or II type-does not exist. As a result of the excess the initial states spectrum is substituted by another spectrum. Further increase of $\rho$ can lead to the excess of at least one of the values $b_{\mathrm{ek}}$. As a result of this the condition (3.27) of the state existence $\left(\Gamma_{\mathrm{ek}}, \mathrm{H}_{\mathrm{ek}}\right)$ is violated. The first to disappear are unstable equilibrium states, for example a certain state $\left(\Gamma_{\mathrm{ij}}, \mathrm{H}_{\mathrm{ij}}\right)$. As soon as $\mathrm{r}$ exceeds $b_{\mathrm{ij}}=\max \left\{b_{\mathrm{ek}}\right\}$ it is the state (3.32) with zero biomass which becomes stable. In this way under $\rho>\max \left\{b_{\mathrm{ek}}\right\}$ the population is completely eliminated.

Presented in Table 3.2 are possible kinds of EG spectra as a function of the pattern of deviation functions $\sigma_{\mathrm{k}}(S)=0, \mathrm{k}=1,2$, with the chains of transitions from one spectrum to another with the increase in the specific elimination rate $\rho$. If $d_{1}<d_{2}$ (or $d_{1}>d_{2}$ ), then $i=1$ (or

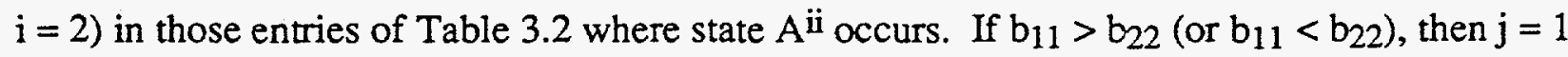
(or $\mathrm{j}=2$ ) in symbols $B_{12}^{\mathrm{jj}}$ and $C_{\mathrm{ij}}$. Whether the chains of transitions shown for Types III and IV of Table 3.2 can be completely realized depends on the value $\mathrm{R}$ of the limiting-resource inflow. For example, if both deviation functions $\sigma_{\mathrm{k}}(S), \mathrm{k}=1,2$, exhibit Type III behavior, then complete 
realization of a transition chain from the entry for Type III-Type III in Table 3.2 is possible only when

$$
\mathrm{R} / \mathrm{D}>\max \left\{c_{1}, c_{2}\right\} .
$$

If

$$
\min \left\{c_{1}, c_{2}\right\}<R / D<\max \left\{c_{1}, c_{2}\right\},
$$

then only the transition chain of the entry for Type I-Type III (when $c_{1}<c_{2}$ ) or that of the entry for Type III-Type I (when $c_{1}>c_{2}$ ) can be completely realized. If

$$
\mathrm{R} / \mathrm{D}<\min \left\{\mathrm{c}_{1}, \mathrm{c}_{2}\right\} \text {, }
$$

then the transition chain for entry Type I-Type I is realized.

Generally, increasing in the specific rate of elimination, $\rho$, brings about disappearance of equilibrium states, and the chain of EG spectrum transitions becomes $A \rightarrow B \rightarrow C$. Increasing $R$ or $\mathrm{R} / \mathrm{D}$ leads to expansion of the EG spectrum, and the reverse chain takes place: $\mathrm{C} \rightarrow \mathrm{B} \rightarrow \mathrm{A}$.

A remarkable property of the model in Equations 3.15-3.18 is that a stable genetic polymorphism many exist under a single resource-limiting condition for the growth of all genotypes. Hence, the well-known competition exclusion principle of interspecies ecology cannot be projected to intraspecies relations among individuals of different genotypes. This model also calls into question a direct relation between the genotypic, and respectively the phenotypic, variability of a population and the diversity of its habitat conditions, the paradigm that has been enunciated since the work of Cunha et al. (1950; see also Cunha and Dobzhansky, 1954; Soule, 1976; Valentine, 1976; Nevo et al., 1984). It would be incorrect to overestimate the role this relation plays in the genetic diversity observed in plant populations and to explain the latter exclusively by the diversity of habitats and the diverse adaptation of genotypes to those habitats.

\section{DISCUSSION}

Background Comments. Equations like Equations 3.3-3.4 or 3.17-3.18, which do not take into account the genetic variability of the population, form the foundation of a mathematical theory for trophic competition among species (Abrosov and Kovrov, 1977) that has come to be 
known most commonly as the resource competition theory and is commonly associated with the work of Tilman (1982). The basis for this theory (Abrosov, 1975; Abrosov and Kovrov, 1977; Abrosov et al., 1982; Abrosov and Bogoliubov, 1988), which has received support in experiments on unicellular organisms (Furyaeva et al., 1976; Abrosov et al., 1977; Tilman, 1977, 1981; Grover, 1988), has been recently used to explain the outcomes of competition among terrestrial vascular plants (McGraw and Chapin, 1989; Pidwirny, 1990; Tilman and Wedin, 1991a; Wilson and Tilman, 1991). These ideas are the basis for expanding the theory of plant community succession (Tilman, 1985, 1987; Inoye et al., 1987; Carson and Barrett, 1988; Tilman and Wedin, 1991b), revealing the nature of species domination (Tilman, 1982, 1987), revisiting the competition exclusion principle (Bogoliubov, 1989), and accounting for factors that sustain species diversity in communities (Abrosov et al., 1982; Tilman, 1982; Abrosov and Bogoliubov, 1988; Onipchenko, 1988; Bogoliubov, 1989). In addition, attempts have been made to relate views on vegetation strategies (Grime, 1979) to the theory of trophic competition (Tilman, 1988; Romanovsky, 1989; Grace, 1990). Grime's triangular model has been subject to criticism (see, e.g., Loehle, 1988) and barely finds an adequate explanation within the theory of trophic competition.

Within the theory, most attention is focused on the dynamics of the population biomass. Therefore, compromises are inevitable in the description of the manifold reactions of plants to the effects of competition. Major applications of the trophic competition theory have occurred in cases of interspecies competition for noninterchangeable resources. The most pertinent interpretations were given to outcomes of experiments on perennials. Nevertheless, the model of biomass dynamics for a population consuming several noninterchangeable nutrients under intraspecies competition, which is used as the basis for the interspecies competition model, still needs experimental verification. Whether these theoretical views are valid for explaining trophic competition among plants during a single vegetation period is also unclear.

In the construction of the model in Equations 3.1-3.4 and its special case in Equations 3.15-3.18, a weakness concerns the assumption that the plant biomass $\mathrm{X}$ is proportional to the 
population size $\mathrm{N}$. The assumption has led to good agreement between the theory and data on interspecies competition among diatomic algae (Tilman, 1981). However, transferring the assumption immediately to vascular plants, as was done by Tilman $(1982,1988)$, should be performed with extreme care. The problem is that recent experiments (Bogoliubov, 1993) have verified equations like Equations 3.17-3.18 as a means to describe the outcome of intraspecies competition in the Italian rye grass Lolium multiflorum within one vegetation period, although the population density was constant $(\mathrm{dN} / \mathrm{dt} \equiv 0)$ in those experiments. In fact, the biomass did vary, naturally violating the assumption of the model (2.1-2.4).

We have not yet learned to adequately model joint dynamics of the population density $\mathrm{N}$ and its biomass $\mathrm{X}$. To do so requires pertinent life history models of plants. The surprisingly persistent positive correlation commonly observed between the density of a population and any other index of its abundance gives an argument in favor of the proportionality assumption. If, in addition, the biomass value is considered to be averaged over the annual period, then the assumption may hold much more validity. However, to truly substantiate the assumption, we need a well-tested theory for life histories of plants.

\section{On the Role of Genotype-Invariant Influencies or Undifferential Influences on a Selection.} According to the most common views, nonselective elimination cannot substantially modify the genetic structure of a population. If, indeed, the elimination is not selective, then the genotypes of the population are eliminated in proportion to their relative abundances. This is just what the model in Equations 3.15-3.18 indicates. Separation of genetic laws from ecological processes feeds an illusion that nonselective elimination cannot create directional changes. Shmalgausen (1968, 1983), however, stated that nonselective elimination results in fecundity selection. Shwarts (1980) also questioned the moderate role ascribed to nonselective elimination; he proposed that "whatever the immediate reasons causing population ecological structure change (including nonselective elimination), the result is population genetic structure change" (Shwarts, 1980, p. 191). As a justification for his theoretical speculations, he cited the work of Pavlov (1965), who studied, by his request, the dynamics of polymorphism in squirrels and revealed that changes in harvesting 
pressure have a directional effect on the population genetic structure. Studies of the class of Fisher models for density-dependent selection showed (Konovalov, 1974) that a genotype-invariant harvesting pressure results in alteration of the population genetic structure.

The variety of transition chains in the population's EG spectra provides strong evidence that changes in the non selective elimination rate, $\rho$, may alter the equilibrium frequencies of genotypes, stabilize or destabilize a genetic equilibrium, or even result in the loss or gain of an equilibrium state. Thus, the model in Equations 3.15-3.18 presents a tool for analyzing the issue in greater detail. According to the model, various habitat conditions of a population imply various spectra of its ecogenetic structures. The existence and stability of a steady ecogenetic state are determined by the habitat conditions, which are the basis for directional alteration and control of the population genotype and phenotype structures.

Moreover, the study of models $3.15-3.18$ shows that when the growth of all genotypes is limited by a single resource, population genetic state will also change under the influence of another habitat condition characteristic, namely the resource inflow rate $\mathrm{R}$. The population reacts only to the resource concentration in the environment; the resource inflow rate doesn't provide selective influence upon genotypes. At the same time it belongs to the existence and stability conditions for equilibrium states. Therefore, a decrease in the resource inflow can, for example, destabilize and annihilate an equilibrium genetic state.

In models of intraspecies competition for two nutrient resources, changes in the input resource concentrations can result in changes in the habitat concentrations of the resources. Because the genotypes differ in their uptake rates, the population genetic structure is altered (Abrosov and Bogoliubov, 1988; Bogoliubov, 1992).

Thus, changes in habitat conditions that cause no immediate selective effects on the genotypes of a population can nevertheless produce directional alterations in its genetic structure, either by changing steady-state concentrations of nutrient resources or through destabilization or loss of the current equilibria or emergence of new ones. 
On Seed Sources. Our thesis to test: "If the major part of genetic variability can be found in any local population of plants, then the specific source of seeds used in particular revegetation efforts does not matter." This is a common assumption in restoration efforts.

Consider two populations, $\mathrm{A}$ and $\mathrm{B}$, of a plant species, in which, for any genotype $\mathrm{g}$ in population $A$, at least one plant of the same genotype is in population $B$ and vice versa. In other words, the set of all genotypes present in population $A, G_{A}=\left\{g_{1}^{A}, g_{2}^{A}, \ldots, g_{m}^{A}\right\}$, coincides with that in population $B, G_{B}=\left\{g_{1}^{B}, g_{2}^{B}, \ldots ., g_{m}^{B}\right\}$. Let the frequencies of the genotypes be $u^{A}=\left(u_{1}^{A}\right.$, $\left.u_{2}^{A}, \ldots, u_{m}^{A}\right)$ in population $A$ and $u^{B}=\left(u_{1}^{B}, u_{2}^{B}, \ldots, u_{m}^{B}\right)$ in population $B$. Suppose generally that $\mathbf{u}^{\mathrm{A}} \neq \mathbf{u}^{\mathrm{B}}$. Let the genotype frequency vector for the seeds produced by population $\mathrm{A}$ in a particular year be denoted by

$$
\mathrm{s}^{\mathrm{A}}=\left(\mathrm{s}_{1}^{\mathrm{A}}, \mathrm{s}_{2}^{\mathrm{A}}, \ldots, \mathrm{s}_{\mathrm{k}}^{\mathrm{A}}\right)
$$

and that for population $B$ by

$$
\mathbf{s}^{\mathrm{B}}=\left(\mathrm{s}_{1}^{\mathrm{B}}, \mathrm{s}_{2}^{\mathrm{B}}, \ldots, \mathrm{s}_{\mathrm{k}}^{\mathrm{B}}\right),
$$

with $k$ being not necessarily equal to $m$. If $G_{A}=G_{B}$ but $\mathbf{u}^{A} \neq \mathbf{u}^{B}$, then $\mathbf{s}^{A} \neq \mathbf{s}^{B}$.

Suppose that we sample a quantity $\mathrm{N}_{\mathrm{A}}$ of seed produced by population $\mathrm{A}$ and a quantity $\mathrm{N}_{B}$ from population B. If the samples are representative, then the genetic structures of the samples, $\widetilde{\mathbf{s}}^{A}$ $\neq \tilde{\mathbf{s}}^{\mathrm{B}}$, may differ only insignificantly from those of the populations:

$$
\tilde{\mathbf{s}}^{\mathrm{A}} \cong \mathbf{s}^{\mathrm{A}}, \tilde{\mathbf{s}}^{\mathrm{B}} \cong \mathbf{s}^{\mathrm{B}} \text {. }
$$

Particular values of $\mathrm{N}_{\mathrm{A}}, \tilde{\mathrm{s}}^{\mathrm{A}}$ and $\mathrm{N}_{\mathrm{B}}, \tilde{\mathrm{s}}^{\mathrm{B}}$ may correspond to the initial conditions for model dynamics of the population size and genotype frequencies of populations involved in particular revegetation efforts (for instance, after mining). If we were sure that the outcome of microevolution in the plant population did not depend on the initial conditions, then the source of seeds used in the revegetation would not matter, subject to the condition that $G_{A}=G_{B}$. However, even single-locus dynamic models show that a nonempty set of conditions may guarantee the existence of disruptive selection (domain $E_{4}$ in Figures 2.1 and 2.2 or spectra $A_{12}$ and $\mathrm{B}_{22}^{11}$ in Table 3.1). Therefore, the outcome of intraspecies competition among genotypes could be dependent on the initial conditions of revegetation. 
Strictly speaking, to produce different outcomes of model dynamics the differences in the initial conditions must be sufficient to cause two initial points to belong to different domains of attraction of two stable equilibria. The situation where small differences lead to different outcomes may correspond to the case where the initial state of the population happens to be near the boundary between the domains of attraction. This situation might also be reminiscent of the divergence phenomenon known in catastrophe theory models for close initial points located on opposite sides of the (nontrivial) equilibrium manifold (Loehle, 1989). In any case, even if we can find the same set of loci and their alleles in each local population, we cannot believe the outcome of revegetation efforts is independent of the seed source chosen. The exception will be when selection is predominately at a single locus, as in selection for heavy-metal tolerance on mine spoil land (McNeilly, 1988), when other genotypes are nonviable.

The existence of multiple domains of attraction and sensitivity to initial conditions (of seed source) demonstrated by our linked genetics-resource use model has interesting implications. If these model results hold in the field, then a significant component of genetic variation between local populations could result from these dynamic interactions and is not necessarily a reflection of between-site differences in environment. This also means that "founder effects" can result even when founding populations are not extremely small, because differences in initial conditions will be amplified during subsequent selection. This mechanism for generating genetic spatial heterogeneity in spite of a uniform environment is similar to the model studies showing generation of spatial pattern in population abundance in host-parisitoid systems (Hassell et al., 1994) and the potential generation of multiple end communities during ecosystem assembly experiments (Drake, 1991), demonstrated with both models and in microcosms. Thus several lines of evidence point to spatial heteorogeneity resulting from the complexity of species or genotype interactions, as well as from spatial environmental heterogeneity and succession/disturbance effects.

Overall, the analysis presented here identifies some of the unique features of selection during revegetation events and indicates that selection for local adaptation (microevolution) is not 
necessarily straightforward. From these conclusions we urge that greater thought be given to seed/propagule source and population genetic structure during vegetation restoration efforts.

\section{ACKNOWLEDGMENTS}

This research is supported through contract W-31-109-ENG-38 with the U.S. Department of Energy, Office of Energy Research, Office of Health and Environmental Research, Program for Ecosystem Research. This manuscript was improved by the comments of Dmitrii Logofet, Jasha

Gall, and Vladimir Passekov. Editorial assistance provided by Karen Haugen and Yelena Bogoliubova. 


\section{REFERENCES}

Abrosov, N. S. 1975 . Theoretical study of a mechanism to regulate the species structure in a community of autotrophs. Ecologiya, No. 6: 5-14 (in Russian).

Abrosov, N.S. and A.G. Bogoliubov. 1985. Theoretical analysis of ecologo-genetic structure of populations and communities. I. The construction of dynamics equations of ecologogenetic population structure. Genetika, 21(6):964-971. (In Russian).

Abrosov, N.S. and A.G. Bogoliubov. 1985. Theoretical analysis of ecologo-genetic structure of populations and communities. II. The model study by population logistic growth. Genetika, 21(6):972-977. (In Russian).

Abrosov, N. S. and Bogoliubov, A. G. 1988. Ecological and Genetical Regularities of Species Coexistence and Coevolution. Nauka, Siberia Branch, Novosibirsk, 333 pp. (in Russian). Abrosov, N. S. and Kovrov, B. G. 1977. Studying the Species Structure at the Trophic Level of Unicells. Nauka, Siberia Branch, Novosibirsk, 190 pp. (in Russian).

Abrosov, N. S., Kovrov, B. G., and Cherepanov, O. A. 1982. Ecological Mechanisms of Coexistence and Species Regulation. Nauka, Siberia Branch, Novosibirsk, 302 pp. (in Russian).

Abrosov, N. S., Pechurkin, N. S., and Furyaeva, A. V. 1977. Studying competition among heterotroph organisms. Ecologiya, No. 5: 45-51 (in Russian).

Ashby, W. C. Forests. 1987. pp. 89-108, in W. R. Jordan, III., M. E. Gilpin, and J. D. Aber (eds.) Restoration Ecology. Cambridge University Press, Cambridge.

Bogoliubov, A. G. 1989. On the competition exclusion principle and mechanisms to sustain species diversity in communities. Biologicheskie Nauki (Biological Sciences), No. 11: 5-18 (in Russian).

Bogoliubov, A. G. 1991. Criticizing the mathematical grounds for synthetic theory of evolution. pp. 99-103, in G. S. Rozenberg, Ed., Theoretical Issues of Evolution and Ecology, Institute for Ecology of the Volga Watershed, USSR Acad. Sci., Tol'yatti. (in Russian) 
Bogoliubov, A. G. 1992. On the coevolutionary mechanisms of species diversity maintenance. pp. 171-180, in B.A. Yurtsev, Ed., Biological Diversity: The Approaches to the Study and Conservation. Ruşian Academy of Science, Zoological Institute, Botanical Institute Russian Botanical Society, St. Petersbury (in Russian).

Bogoliubov, A. G. 1993. Theoretical predictions and experimental tests of intraspecies competition outcomes. The density invariance. Botanicheskii Zhurnal (Botanical Journal), 78, No. 2: 1-14 (in Russian).

Bogoliubov, A. G. and Abrosov, N. S. 1985. Dynamics of the ecologo-genetical structure of a population under intraspecies competition for the substrate in the chemostat conditions. pp. 121-134 , G. S. Rozenberg, Ed., Mathematical Biophysics, Krasnoyarsk State University, Krasnoyarsk (in Russian).

Bogoliubov, A. G., Abrosov, N. S., and Terskov, I. A. 1986. Species coevolution under trophic competition. Daklady AN SSSR, 286, No. 2: 443-447. English translation: ???

Carson, W. P. and Barrett, G. W. 1988. Succession in old-field plant communities: Effects of contrasting types of nutrient enrichment. Ecology, 69, No. 4: 984-994.

Da Cunha, A. B., Burla, H., and Dobzhansky, Th. 1950. Adaptive chromosomal polymorphism in Drosophila willistoni. Evolution, 4, No. 3: 212-235.

Da Cunha, A. B. and Dobzhansky, Th. 1954. A further study of chromosomal polymorphism and its relation to the environment. Evolution, 8, No. 1: 8-17.

Drake, J. A. 1991. Community assembly dynamics and the structure of an experimental species ensemble. American Naturalist, 137:1-2.

Ellstrand, N. C. and D. R. Elam. 1993. Population genetic consequences of small population size: Implications for plant conservation. Annual Reviews Ecology Systematics 24:217-242.

Furyaeva, A. V., Philippova, G. I., and Gladchenko, A. M. 1976. Coexistence of diverse yeast species in a continuous culture. Gidroliznaya i Lesohimicheskaya Promyshlennost (Hydrolysis and Forest-Chemistry Industry), No. 4: 9-19 (in Russian). 
Grace, J. B. 1990 . On the relationship between plant traits and competition ability. p. 51-65. in: J. B. Grace and D. Tilman (Eds). Perspectives on Plant Competition, Academic Press, San Diego, California.

Greig, J. C. 1979. Principles of genetic conservation in relation to wildlife management in Southern Africa. S. Afr. Tydskr. Naturnav, 9, No. 9:57-78.

Grime, J. P. 1979. Plant Strategies and Vegetation Processes, John Wiley, Chichester, 222 pp.

Grover, G. P. 1988. Dynamics competition in a variable environment: Experiment with two diatom species. Ecology, 69, No. 1: 408-417.

Hassell, M. P., H. N. Comins, and R. M. May. 1994. Species coexistence and self-organizing spatial dynamics. Nature, 370:290-292.

Inoye, R. S., Huntly, N. J., Tilman, D., et al. 1987. Old-field succession on a Minnesota sand plain. Ecology, 68, No. 1: 12-26.

Konovalov, N.Y. 1975. On the exploitation of genetically heterogeneous populations. Journal of General Biology, 36(4):498-503. (In Russian).

Kostitzin, V. A. 1978. General differential equations for the problem of natural selection. pp. 424-426 in F. M. Scudo and J. R. Ziegler, Eds., The Golden Age of Theoretical Ecology: 1923 1940. A Collection of Works by V. Volterra, V. A. Kostitzin, A. J. Lotka, and A. N. Kolmogoroff (Lecture Notes in Biomathematics, Vol. 22), Springer, Berlin.

Ledig, F. T. 1986. Heterozygosity, heterosis, and fitness in outbreeding plants. p. 77-104, In: M. E. Soule (ed.) Conservation Biology. Senauer Associates, Sunderland, Massachusetts. Loehle, C. 1988. Problems with the triangular model for representing plant strategies. Ecology, 69, No. 69: 284-286.

Loehle, C. 1989. Catastrophe theory in ecology: A critical review and an example of the butterfly catastrophe. Ecological Modelling, 49:125-152.

Logofet, D. O. 1993. Matrices and Graphs: Stability Problems in Mathematical Ecology, CRC Press, Boca Raton, Florida, 308 pp. 
McGraw, G. B. and Chapin, F. S. 1989. Competitive ability and adaptation to fertile and infertile soils in two Eriophorum species. Ecology 79, No. 3: 736-749.

McNeilly, T. 1988. Evolutionary lessons from degraded ecosystems. pp. 271-286 in: W. R. Jordan III, M. E. Gilpin, and J. D. Aber (eds.). Restoration Ecology, Cambridge University Press, Cambridge.

Meffe, G. K. and C. R. Carroll. 1994. Principles of Conservation Biology, Sinauer Association, Sunderland, Massachusetts. $600 \mathrm{pp}$.

Munshower, F. F. 1993. Practical Handbook of Disturbed Land Revegetation, CRC Press, Boca Raton, Florida.

Nevo, E., A. Beiles, and R. Ben-Shlomo. 1984. The evolutionary significance of genetic diversity: ecological, demographic, and life history correlates. pp. 13-213 in: G.S. Mani (ed.). Evolutionary Dynamics of Genetic Diversity. Springer-Verlag, New York.

Onipchenko, V. G. 1988. Mechanisms to sustain species richness of phytocenoses: Problems and research perspectives. pp. 5-10, in K. Kull and T. Ksenofontova, Eds., Perspectives of Phytocenology Theory, Estonian SSR Academy of Science, Tartu. (in Russian).

Pavlov, B.K. 1965. Phenotypic variability in the Eastern Siberia population of squirrels. Bulletin MOIP Biology Section, 70(3):131. (In Russian).

Pidwirny, M. J. 1990. Plant zonation in a brackish tidal marsh: Descriptive verification of resource-based competition and community structure. Canadian Journal of Botany, 68, No. 8: 1689-1697.

Powers, J. 1988. Restoration practice raises questions. pp. 85-87 in: W. R. Jordan III, M. E. Gilpin, and J. D. Aber (eds.), Restoration Ecology, Cambridge University Press, Cambridge.

Romanovsky, Yu. E. 1989. Current state of the concept of life-cycle strategies. Biologicheskie Nauki (Biological Sciences), No. 11: 18-31 (in Russian).

Schmalhausen, I.I. 1949. Factors of Evolution: The Theory of Stabilizing Selection. Trans. Blakiston, Philadelphia. 
Schmalgausen, I. I. 1969. Factors of Evolution: A Theory of Stabilizing Selection. (p. 28) Nauka, Moscow, 451 pp. (in Russian).

Schmalgausen, I. I. 1983. Directions and Regularities of the Evolutionary Process. Selected Works, Nauka, Moscow, 360 pp. (in Russian).

Shwarts, S. S. 1980. Ecological Laws of Evolution. Nauka, Moscow, 278 pp. (in Russian).

Soule, M. 1976. Allozyme variation: Its determination in space and time. pp. 60-77, in F. J. Ayala, Ed., Molecular Evolution, Sinauer, Sunderland.

Svirezhev, Y. M. and Logofet, D. O. 1983. Stability of Biological Communities, Mir Publishers, Moscow, 319 pp. (revised from 1978 Russian edition).

Svirezhev, Yu. M. and Passekov, V. P. 1982. Fundamentals of Mathematical Evolutionary Genetics, Nauka, Moscow, (in Russian) English translation: 1990, Kluwer (D. Reidel), Dordrecht, 395 pp.

Templeton, A. R. 1986. Coadaptation and outbreeding depression. p. 105-116, In: M. E. Soule (ed.) Conservation Biology. Sinauer Associates, Sunderland, Massachusetts.

Tilman, D. 1977. Resource competition between planktonic algae: An experimental and theoretical approach. Ecology, 58, No. 2: 338-348.

Tilman, D. 1981. Tests of resource competition theory using four species of Lake Michigan algae. Ecology, 62, No. 3: 802-815.

Tilman, D. 1982. Resource Competition and Community Structure, Princeton University Press, Princeton, New Jersey, 360 pp.

Tilman, D. 1985. The resource ratio hypothesis of succession. American Nature, 125, No. 6: 827-852.

Tilman, D. 1987. On the meaning of competition and the mechanisms of competitive superiority. Func. Ecology, No. 1: 304-315.

Tilman, D. 1988. Plant Strategies and the Dynamics and Structure of Plant Communities, Princeton University Press, Princeton, New Jersey, 360 pp. 
Tilman, D. and Wedin, D. 1991a. Plant traits and resource reduction for five grasses growing on a nitrogen gradient. Ecology, 72, No. 2: 683-698.

Tilman, D. and Wedin, D. 1991b. Dynamics of nitrogen competition between successional grasses. Ecology, 72, No. 3: 1038-1049.

Valentine, J. W. 1976. Genetic strategies of adaptation. pp. 78-94, in F. J. Ayala, Ed., Molecular Evolution, Sinauer, Sunderland.

Wilson, S. D. and Tilman, D. 1991. Components of plant competition along an experimental gradient of nitrogen availability. Ecology, 72, No. 3: 1050-1065. 
Table 2.1 Existence conditions of equilibrium states $\mathrm{Q}_{11}, \mathrm{Q}_{12}, \mathrm{Q}_{22}$ and of population neutral states and the eigenvalues $\lambda_{1}, \lambda_{2}, \lambda_{3}$.

\begin{tabular}{|c|c|c|c|c|}
\hline State & Existence Conditions & $\lambda_{1}$ & $\lambda_{2}$ & $\lambda_{3}$ \\
\hline$Q_{11}$ & $\left|\sigma_{1}\right|+\left|\sigma_{2}\right| \neq 0$ & $\sigma_{1}$ & $-\alpha_{11}$ & $-\alpha_{11}$ \\
\hline$Q_{22}$ & $\left|\sigma_{1}\right|+\left|\sigma_{2}\right| \neq 0$ & $\sigma_{2}$ & $-\alpha_{22}$ & $-\alpha_{22}$ \\
\hline$Q_{12}$ & $\sigma_{1} \sigma_{2}>0$ & $-\frac{\sigma_{1} \sigma_{2}}{\sigma_{1}+\sigma_{2}}$ & $-\hat{\alpha}$ & $-\hat{\alpha}$ \\
\hline Neutral & $\sigma_{1}=0, \sigma_{2}=0$ & 0 & $-\alpha$ & $-\alpha$ \\
\hline
\end{tabular}


Table 3.1. Classification of spectra of ecogenetic population structures. ${ }^{a}$

\begin{tabular}{cccc}
\hline EG Spectrum & $\left(\Gamma_{11}, \mathbf{H}_{11}\right)$ & $\left(\Gamma_{12}, \mathbf{H}_{12}\right)$ & $\left(\Gamma_{22}, \mathbf{H}_{22}\right)$ \\
\hline $\mathrm{A}_{11}$ & + & $\varnothing$ & + \\
$\mathrm{A}_{22}$ & - & $\varnothing$ & - \\
$\mathrm{A}_{12}^{+}$ & - & + & + \\
$\mathrm{A}_{12}^{-}$ & + & $\varnothing$ & + \\
$\mathrm{B}_{22}^{11}$ & + & + & $\varnothing$ \\
$\mathrm{B}_{12}^{11}$ & - & + & - \\
$\mathrm{B}_{12}^{22}$ & $\varnothing$ & $\varnothing$ & $\varnothing$ \\
$\mathrm{C}_{11}$ & + & $\varnothing$ & $\varnothing$ \\
$\mathrm{C}_{12}$ & $\varnothing$ & $\varnothing$ & + \\
$\mathrm{C}_{22}$ & $\varnothing$ & + & \\
\hline
\end{tabular}

aSymbols:

+ , the state exists and is stable,

- , the state exists and is unstable.

$\emptyset$, the state does not exist. 
Table 3.2. Chains of transitions among EG spectra due to increases in the specific rate of elimination.

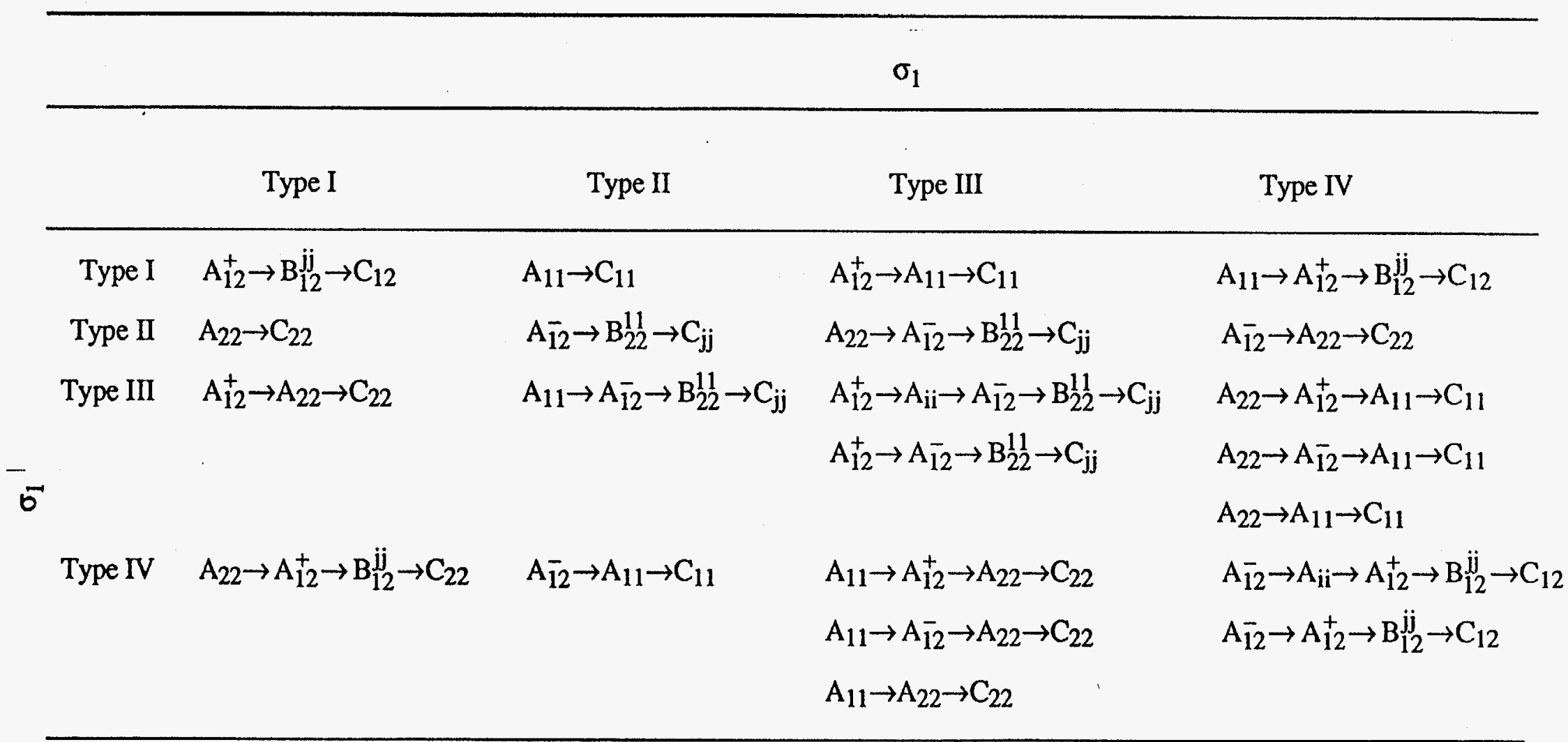




\section{FIGURE CAPTIONS}

Figure 2.1. Structural portrait of Equations 2.18 in the plane $\left(\sigma_{1}, \sigma_{2}\right)$, with $\sigma_{i}=\alpha_{12}-\alpha_{i i}$.

Figure 2.2. Structural portrait of Equations 2.43 with $\sigma_{\mathrm{i}}=\gamma_{12}-\gamma_{\mathrm{ii}}$.

Figure 2.3. Structural portrait of Equations 2.58 in the plane $\left(\varepsilon_{1}, \varepsilon_{2}\right)$, with $\varepsilon_{\mathrm{i}}=\gamma_{12} / \beta_{12}-\gamma_{\mathrm{ii}} / \beta_{\mathrm{ii}}$.

Figure 2.4. The influence of the specific rate of sexual reproduction on the equilibrium allele frequencies $\mathrm{p}$ corresponding to different states of $\mathrm{Q}_{\mathrm{ij}}$. Stable states are marked with continuous lines and unstable states with dotted lines.

Figure 2.5. Possible influence of the intensity of asexual reproduction on the equilibrium allele frequencies in different states of $\mathrm{Q}_{\mathrm{ij}}$. Stable states are marked with continuous lines and unstable states with dotted lines.

Figure 3.1. Basic patterns of deviation functions. 


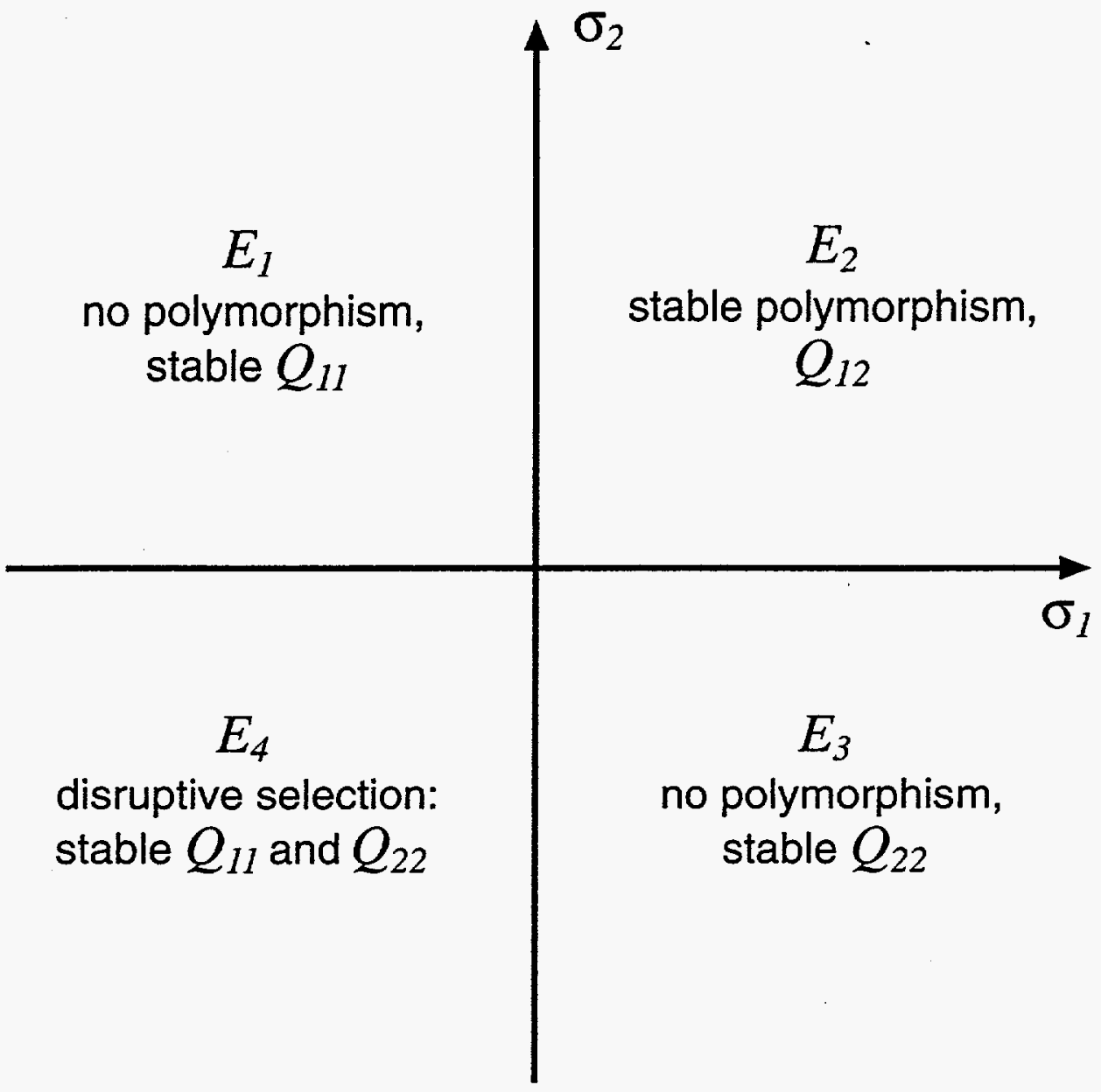

Figure 2.1 


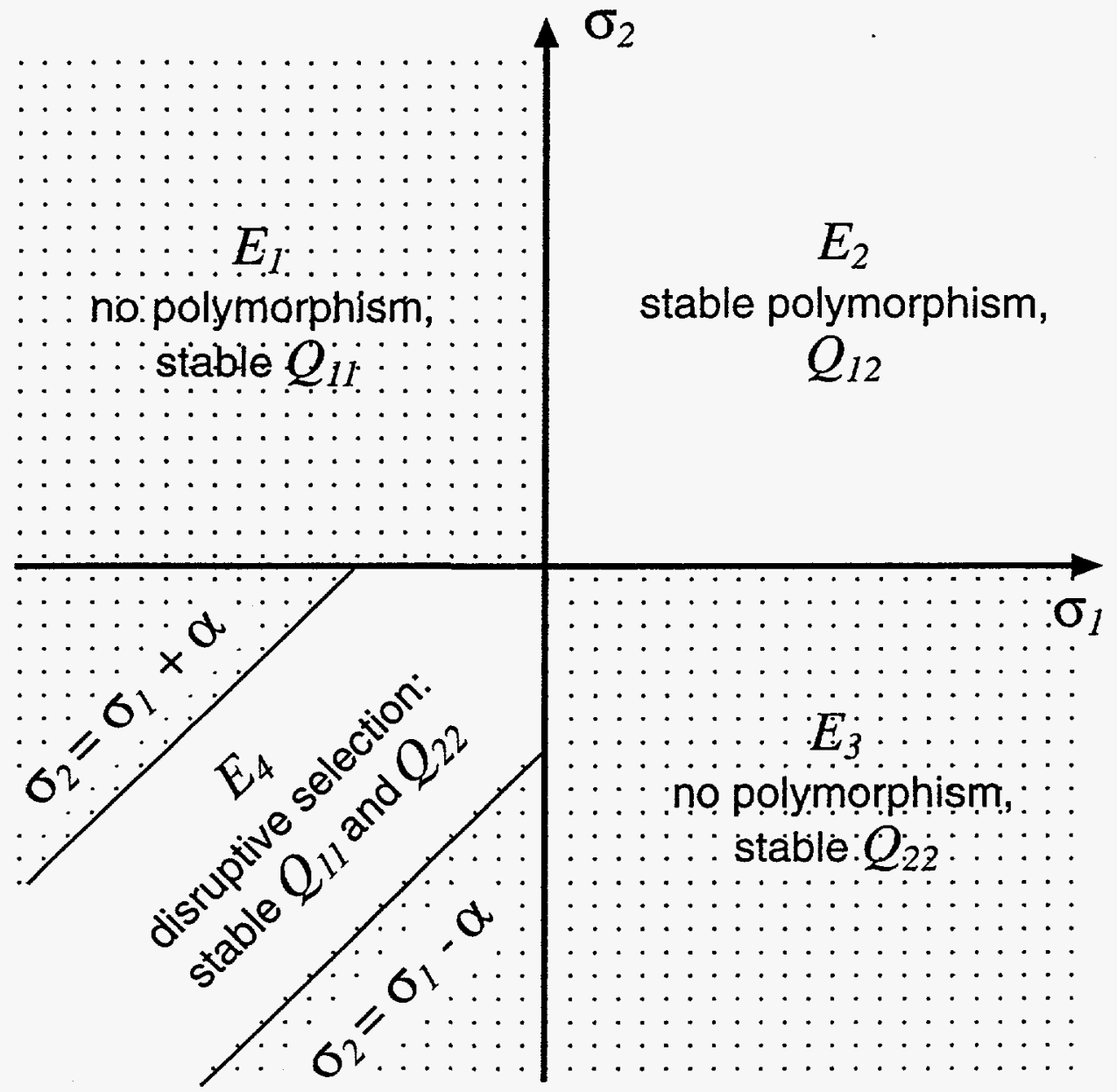

Figure 2.2 


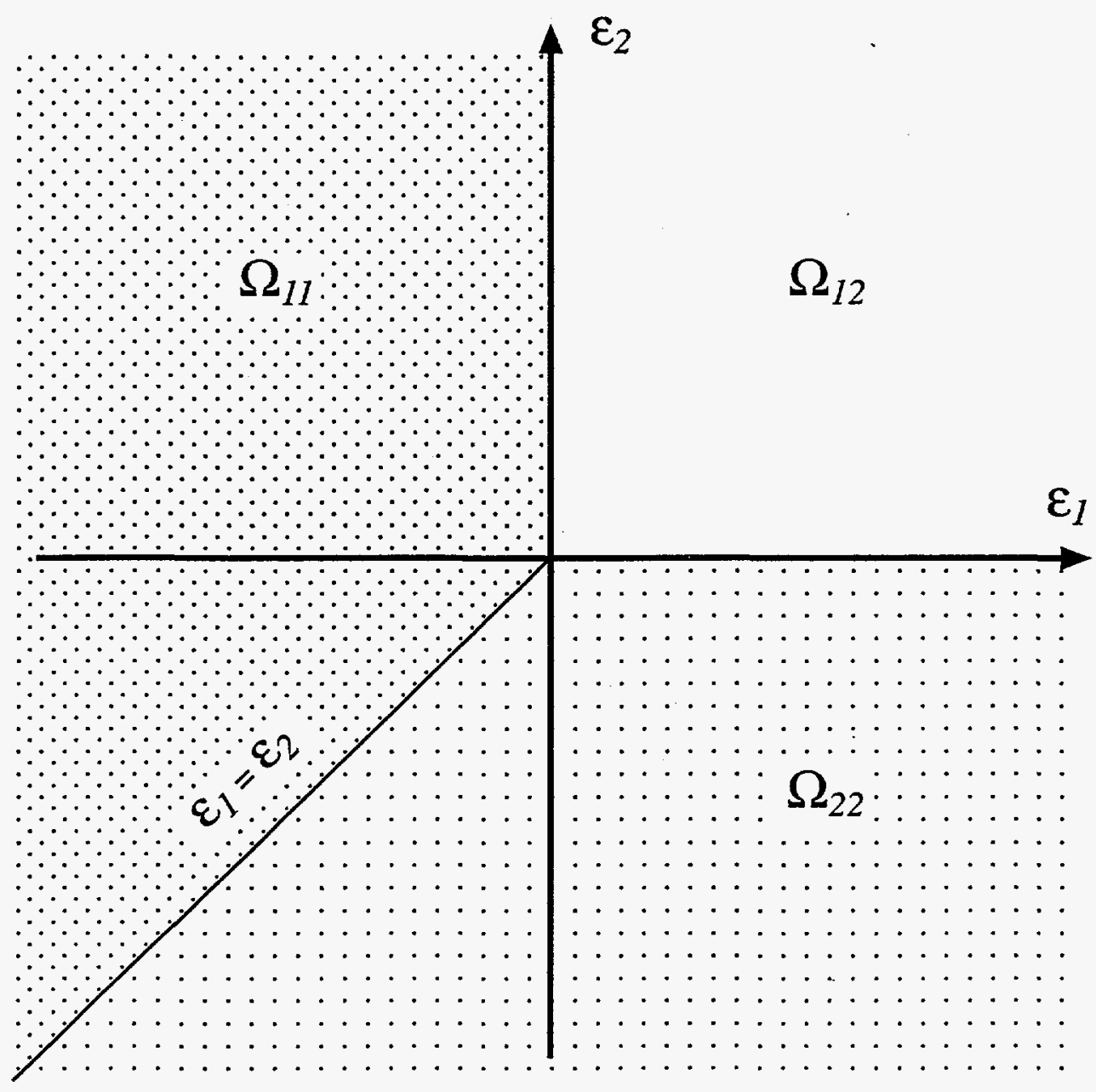

Figure 2.3 

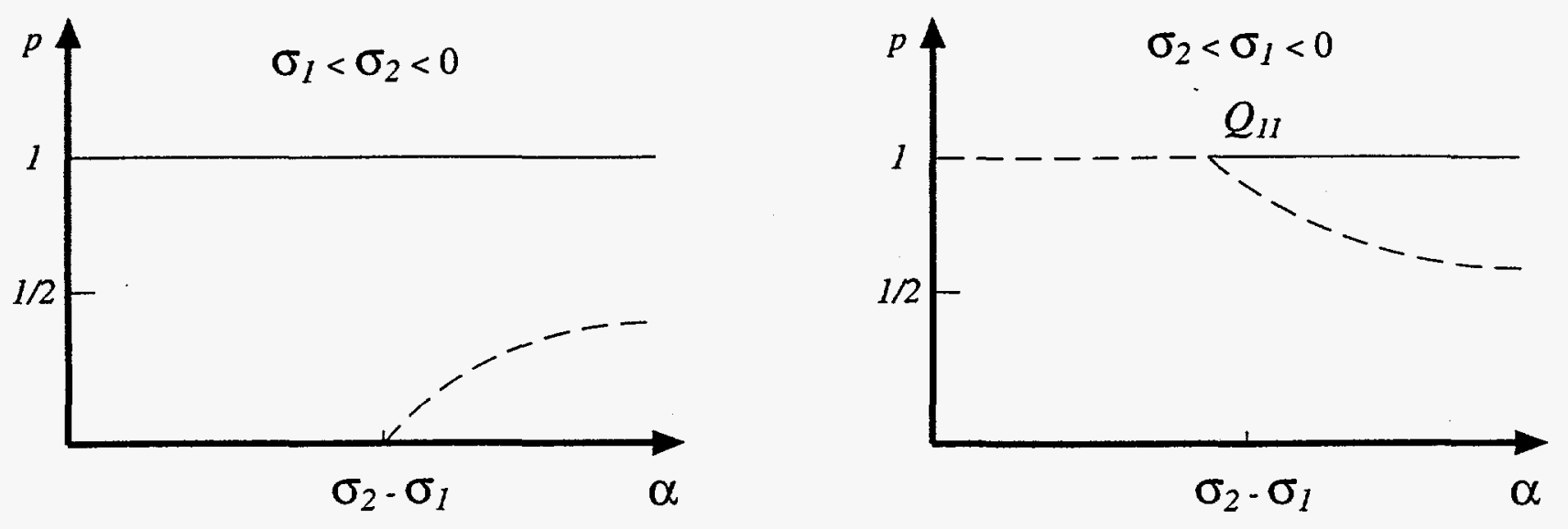

Figure 2.4
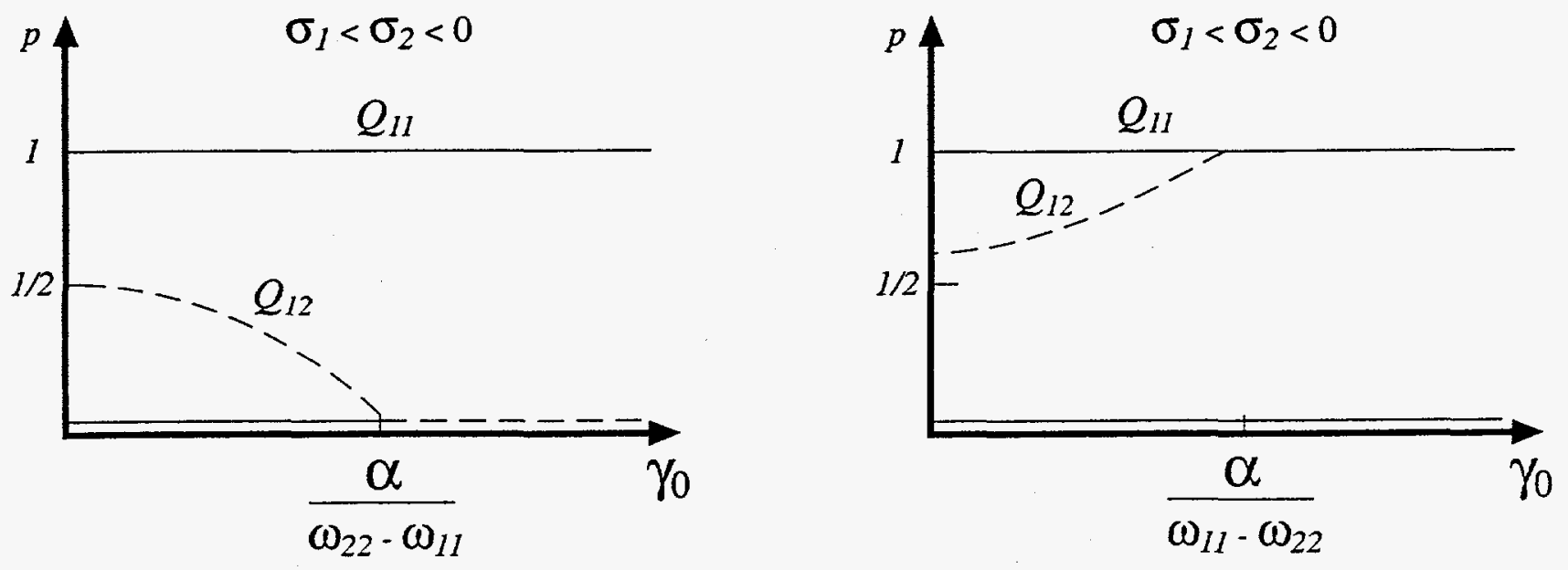

Figure 2.5 


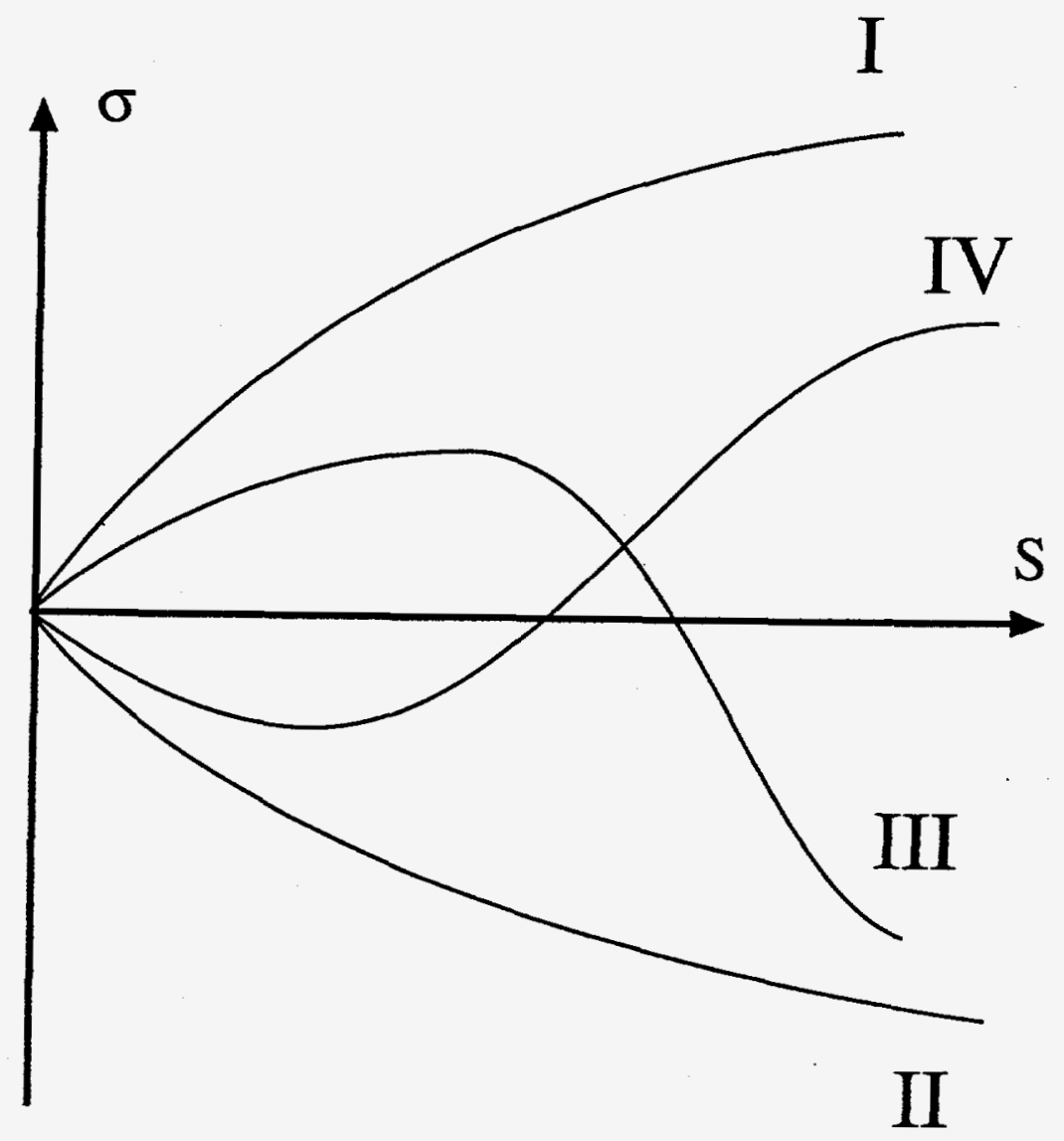

Figure 3.1 